\title{
High-temperature in-process inspection followed by 96- hour robotic inspection of intentionally manufactured hydrogen crack in multi-pass robotic welding
}

\author{
Yashar Javadi $^{1}$, Ehsan Mohseni ${ }^{1}$, Charles N. MacLeod ${ }^{1}$, David Lines ${ }^{1}$, Momchil Vasilev $^{1}$, \\ Carmelo Mineo $^{1}$, Stephen G. Pierce ${ }^{1}$ and Anthony Gachagan ${ }^{1}$ \\ ${ }^{1}$ Centre for Ultrasonic Engineering (CUE), Department of Electronic \& Electrical \\ Engineering, University of Strathclyde, Glasgow G1 1XQ, UK \\ *Corresponding author's email: yashar.javadi@strath.ac.uk
}

\begin{abstract}
This investigation introduces two new techniques to quantitatively address the challenging problem of understanding Hydrogen Induced Cracking (HIC) in welding processes. The first technique is a novel procedure to create a known and controlled HIC in a welded sample. The second is an in-process monitoring technique to measure the initial formation and subsequent growth of the HIC in a multi-pass weld whilst being compatible with the high temperatures associated with the welding process. The HIC was initiated using a localised quenching method of the weld and its character was verified using both macrograph and microscopic investigations. During HIC initiation and growth, the sample was monitored every 1-30 minutes for a total of 96 hours using a custom non-destructive testing (NDT) system, mounted on a robot which ensured repeatable inspection positioning. Combining these techniques has therefore allowed for the first time, a detailed understanding of the evolution of HIC in a multi-pass welded sample. Our findings reveal that the HIC was initiated 43 minutes after the weld ended and that it then grew rapidly for about 15 minutes and continued growing at a slower rate for around 24 hours. No significant growth was observed for the remaining 72 hours of the experimental measurement.
\end{abstract}

Keywords: Hydrogen Induced Cracks; Crack Growth Monitoring; Phased Array Ultrasonic Testing (PAUT); Robotic Welding; Robotic Nondestructive Testing; Intentionally Embedded Defects.

\section{Introduction}

\subsection{Hydrogen Induced Cracks (HIC)}


Hydrogen Induced Cracks (HIC), are cold cracks which occur after welding processes are complete and are the source of many service failures due to fatigue and brittle fracture of welded components. This is an old problem which continues to significantly challenge the industry. Bailey et al [1] described the HIC problem using a historical example in 1973 when it was estimated that in Britain alone annual costs amounting to $£ 260$ million were borne by the industry as a result of manufacturing problems directly attributable to welding. At least $£ 40$ million of this total arose from the need to repair HIC at welds. They explained that even in 2004, the service failure due to fatigue and brittle fracture of welded components cost the industry $£ 140$ million annually (UK figures) and many of these originated from hydrogen cracks at welds.

Although HIC is an old welding problem, Vergani et al [2] explained that the reason behind the HIC formation is a complicated micro-mechanism which is not, despite extensive studies in literature, fully defined to date. However, Lippold [3] summarised the main reasons encouraging the HIC formation and growth as (I) presence of hydrogen (sourced from dust, humidity, etc.), (II) susceptible microstructure and (III) high residual stress. He also showed that the HIC must be categorised as a delayed cracking or cold crack, which means that the initiation and growth of the crack can occur once the weld cools down to a temperature near to normal ambient.

\subsection{Non-destructive testing (NDT) and in-process inspection}

To ensure code compliance (e.g., BS EN 1011-1 [4]), the quality of the weld is required to be evaluated by several quality control methods to rule out the possibility of any defects like the weld cracks, lack of fusion, porosity, etc. If the component is inspected non-destructively, known as Non-Destructive Testing (NDT), and there is no defect larger than the acceptance criteria, the component will pass the quality control without any damage and then it will still be usable $[5,6]$. Traditionally, the welding process and NDT of such welds are separate processes in the supply chain [7]. This can reduce productivity and increase re-work given the necessity of transferring the components between the manufacturing, inspection and repair stations. If these practices are combined directly at the point of manufacture through the use of an automated in-process inspection, it will offer the possibility to control, adapt and consistently ensure high-quality defect-free welding [8]. In the multi-pass welding and Additive Manufacturing (AM), there is increasing motivation to move towards in-process defect detection to enable real-time repair; thus avoiding deposition of more layers over a 
[Type here]

defective weld pass [7]. In the high-value thick components, if the defects are introduced in the lower layers, they can remain undetected until completion and then it will be required to remove all remaining upper layers to re-access the defective lower layer [9]. Alternatively, early detection of such defects using the in-process inspection would reduce the re-work and, even if the weld is not repairable, time and money will still be saved by early scrapping the component [9]. Furthermore, due to the access difficulties to the lower layers, the use of modern in-process inspection can offer fundamental changes to the flexibility and range of possibilities, in terms of complexity and shape, of final fabrications [10].

\subsection{Quantification challenge in NDT of HIC}

Traditional welding and non-destructive testing (NDT) standards usually recommend a delay time (hours to days) between welding and subsequent NDT to avoid any undetected HIC (or other types of delayed defects). For example, Holdstock [11] summarised some of the relevant codes and standards (e.g., BS-EN1011-2:2001) in which a range of 16-96 hours delay between the non-destructive testing (NDT) and welding end time is suggested. However, the standards and literature have few quantitative studies on the delayed time. In this paper, a hydrogen crack is intentionally manufactured in the weld which is inspected for 96 hours to quantify the delay time. The inspection is deployed by a phased array setup mounted on a 6-axis robot. This inspection equipment is part of a larger integration system including welder robot, welding machine, LASER profile measurement, weld monitoring camera, phased array controller and NDT end-effector. The hydrogen crack is also manufactured by a repeatable method and is monitored for four days using in-process welding and inspection system. Application of the following two innovative approaches was included in the work:

(I) Intentionally-manufactured HIC: The idea of intentionally-manufactured weld defect for NDT calibration was used by Javadi et al $[7,8,12]$. They intentionally embedded tungsten components (ball, rod and pipe) in the weld to validate the performance of a robotic NDT system and also calibrate the inspection parameters. However, the defects were either tungsten components [12] or large cracks [7]. The latter was a longitudinal crack created using three experimental techniques: (A) a large weld groove was partially filled with only one pass; (B) the weld length was very short; and (C) the filling wire was specifically selected for that purpose [7]. A key point is that the 
position of that crack was not fully under the control and, if the weld was long, the crack could have a random length [7]. In this paper, the improved manufacturing process of a hydrogen crack is described, where the crack position is defined by the predetermined region of water quenching.

(II) The high-temperature in-process inspection followed by a long-time inspection: The second important part of this paper is the application of an in-process monitoring technique followed by four-day continuous monitoring to inspect the initiation and growth of the HIC using a high-temperature compatible and robotic system. Shull [13] compared several NDT methods considering their advantages and disadvantages. The non-contact NDT techniques can be potentially used in the real-time inspection of the weld. These include thermography, eddy current and X-ray/radiography. However, Cawley [5] explained the lack of practicality and safety issues for radiography inspection, the lower penetration depth of eddy current, potentially a few millimetres, and lower signal-to-noise ratio of the thermography in comparison with the ultrasonic method. This can justify an application of Phased Array Ultrasonic Testing (PAUT) used in this work for the inspection of small HIC in $15 \mathrm{~mm}$ thick samples. Furthermore, there has been little reporting of any type of in-process weld inspection for HIC monitoring other than the ultrasonic technique reported by Pargeter [14]. He evaluated the necessary delay between completion of the welding and start of HIC inspection. A single element ultrasonic probe in an immersion setup was used. However, in his setup, the NDT requirement was to immerse the test samples in the oil bath to cool them to about $40^{\circ} \mathrm{C}$ adjacent to the weld. This cooling time varied between 30 minutes and eight hours, generally 1-3 hours. It is known that the HIC can sometimes be initiated a few minutes after the weld ends so can be missed if the NDT starts with the 30 minute delay in his study. The high-temperature PAUT inspection discussed in this paper avoids the necessity of waiting until the weld has cooled down. The high-temperature in-process inspection was developed by Javadi et al [8] and Lines et al [10] in the multi-pass welding. They used the system for inspection of tungsten defects but, because the purpose of the work was the in-process calibration of a high-temperature inspection system, the inter-pass inspection was required to be accomplished in only a few minutes. Otherwise, the weld could be cooled down below the inter-pass temperature $\left(100^{\circ} \mathrm{C}\right)$ which was a requirement for starting the next subsequent pass [8]. Although the same high-temperature in-process inspection system is used in this paper for the part of the immediate inspection, the inspection time is largely extended from a 
[Type here]

few minutes to about four days. This will ensure that the occurrence of HIC will be detected by the inspection system regardless of the initiation time which can be a few minutes, hours or days after the weld.

It is important to note that the range of 16-96 hours delay between the NDT and welding end time, suggested by the standards [11], is not challenged in this paper. Alternatively, this paper is about the development of a mechanism to continuously monitor the weld (immediately after the weld and then for 96 hours) to validate that standard rule. Furthermore, it is critical to testify that rule with a large number of welds and different welding parameters. For such a comprehensive test with many samples, it is required to use the robotic welding and NDT system, instead of a human operating system, which is considered in this work. It is also known that once a hydrogen crack is detected, the weld is rejected as most of standards and codes have zero tolerance for hydrogen crack (e.g., DNVGL-CG-0051 [15]). However, the continuous monitoring developed in this work will not be stopped if the HIC is detected. This will allow validation of the 16-96 hours rule because it would still be important to quantify the timing for growth of HIC until 96 hours after the weld ends.

It can be argued that an NDT operator could inspect the sample for 96 hours to quantify the delay time. However, it should be noted that the comprehensive and continuous monitoring considered in this paper included (I) high-temperature inspection which was started quickly after the weld and (II) extension of the robotic inspection for 96 hours with the intervals as small as 1 minute. These two steps would not be achieved with the same time-efficiency, repeatability and accuracy if a human testing procedure is used instead of robotic NDT system.

\section{The theoretical background of hydrogen-induced cracking}

The HIC can be encouraged by three main reasons shown in Figure 1: hydrogen existence, microstructure and the residual stress. Barrera et al [16] explained each of these parameters individually and studied the hydrogen sources; e.g., rust, paint, coating, humidity, etc. on the sample, wire or originated from the shielding gas. As highlighted in Figure 1, quenching of the sample (spraying water on the weld) was tested in this study to encourage the HIC. The stress is produced by the external clamping forces combined with the welding residual stress. Javadi [17] investigated the effect of clamp on the Welding Residual Stress (WRS), the stress remaining in the structure in the absence of any external loads or thermal gradients. He used finite element simulation and ultrasonic stress measurement approaches to study two plates, 
welded with and without clamping, and showed that using clamp can considerably increase the WRS. Based on his study, the clamping force was also found as a critical parameter in increasing the WRS. Therefore, the maximum clamping force is implemented in this study by using six clamps (50 KN each) to increase the WRS as a trigger for the HIC (see Figure 1). Withers et al [18] showed that the WRS is linked to the welding parameters, pre-heating and post-weld heat treatment, groove design, welding sequence, etc. They also reviewed many papers focusing on the WRS to measure and reduce this undesired mechanical degradation. Bate and Smith [19] reviewed the application of finite element welding simulation as a good practice allowing a full welding process model to predict and optimise the WRS. For example, they discussed that the WRS can be reduced by an optimised design of weld groove geometry or the welding sequence. Therefore, a 90-degree $\mathrm{V}$ groove, rather than $\mathrm{U}$ groove or 60-degree $\mathrm{V}$ groove which are expected to result in a reduced level of WRS, and a nonsymmetric sequence, rather than symmetrical sequence which can result in lower residual stress, are used in order to produce the maximum possible WRS required for HIC encouragement.

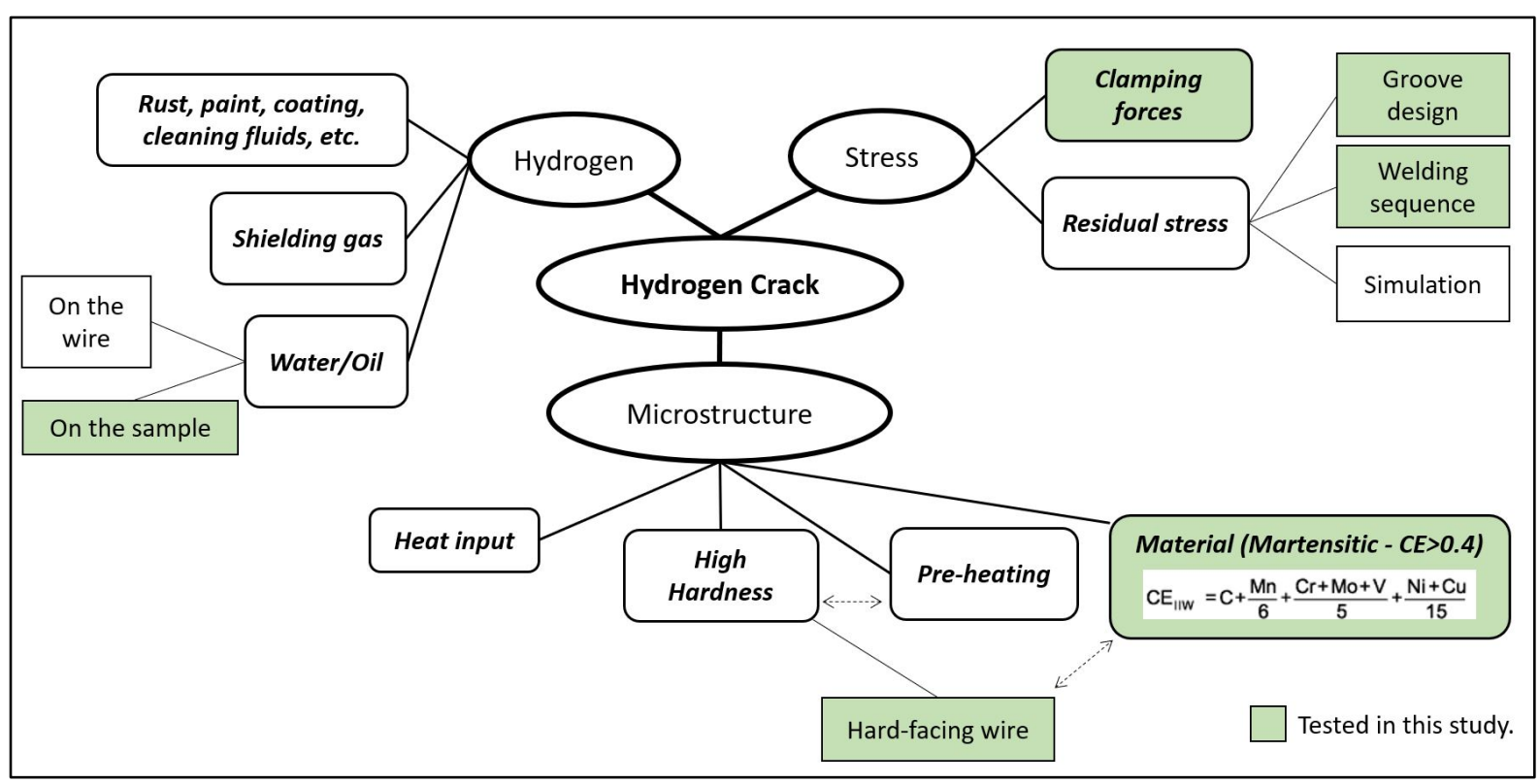

Figure 1. Hydrogen crack mechanism and triggers used in this study

Boniszewski [20] showed that a brittle and hard material is more prone to cracking especially to the hydrogen cracking. He explained that the material hardness can be controlled by the welding heat-input, pre-heating and Carbon Equivalent (CE). Therefore, a high hardness welding wire, which is used for the hard-facing applications, was used in this work to 
[Type here]

increase the weld hardness. This wire has a high amount of carbon $(0.5 \%)$ and then the carbon equivalent $(\mathrm{CE})$ is higher than 0.4 which results in a martensitic structure very prone to the HIC.

\section{Experimental setup}

\subsection{Sample description}

The chosen specimens were $15 \mathrm{~mm}$ thick structural steel (S275) plates of length $300 \mathrm{~mm}$. In total, 21 weld passes were deposited in 7 distinct layers inside a $90^{\circ}$ degree $\mathrm{V}$-groove. Before the root pass, no tack-weld was deposited thanks to the implementation of varied gap method. Because the gap is gradually being closed with the weld moving forward in the root pass, a gap of $2.55 \mathrm{~mm}$ at the start of the weld but $3.3 \mathrm{~mm}$ at the endpoint was used. This has resulted in a consistent gap of $2.55 \mathrm{~mm}$ throughout the weld length. However, closing the root gap at the start was practically difficult and then it was decided to start the weld with lower current (100 A) and as soon as the gap was closed (usually after 5-10 mm and this could be simply confirmed by the weld camera), the current was reverted to the root pass current (120 A). The welding parameters are listed in Table 1. An automatic voltage correction (AVC) system is used to keep the voltage consistent. This approach was possible thanks to a pre-existing software layer equipped with a KUKA software add-on known as Robot Sensor Interface (RSI) as documented by KUKA. RSI runs in a real-time manner to facilitate the communication between the robot controller and an external system (the welder machine in this work) to integrate the robot $\mathrm{Z}$ position and the welding voltage.

The welding layout is shown in Figure 2a. To increase the chance of HIC, some of the welding passes were deposited by a hard-facing wire $(0.5 \% \mathrm{C}, 3 \% \mathrm{Si}, 0.5 \% \mathrm{Mn}, 9.5 \% \mathrm{Cr}$ and Fe: balance) while the normal wire $(0.08 \% \mathrm{C}, 0.85 \% \mathrm{Si}, 1.4 \% \mathrm{Mn}$, and Fe: balance) is used as well (see Figure 2b). Based on the manufacturer reports, the hard-facing wire can achieve 50-60 HRC which is 2-3 times harder than the normal wire.

Table 1. Welding parameters

\begin{tabular}{|l|l|l|c|c|c|c|}
\hline & Voltage (V) & Current (A) & $\begin{array}{c}\text { Travel Speed } \\
(\mathrm{mm} / \mathrm{min})\end{array}$ & $\begin{array}{c}\text { Wire Feed } \\
\text { Speed } \\
(\mathrm{mm} / \mathrm{min})\end{array}$ & $\begin{array}{c}\text { Weaving } \\
\text { Amplitude } \\
(\mathrm{mm})\end{array}$ & $\begin{array}{c}\text { Weaving } \\
\text { Frequency } \\
(\mathrm{Hz})\end{array}$ \\
\hline
\end{tabular}




\begin{tabular}{|c|c|c|c|c|c|c|}
\hline $\begin{array}{c}\text { Layer } 1 \\
\text { (root pass) }\end{array}$ & $\begin{array}{c}\text { AVC* set on } \\
12 \mathrm{~V}\end{array}$ & $100-120^{* *}$ & 50 & 910 & 2 & 0.3 \\
\hline $\begin{array}{c}\text { Layer } 2 \\
\text { (hot pass) }\end{array}$ & 13.5 & 220 & 100 & 1225 & 4 & 0.6 \\
\hline $\begin{array}{c}\text { Layer 3-6 } \\
\text { (filling } \\
\text { passes) }\end{array}$ & 13.5 & 210 & 120 & 1470 & 3 & 0.55 \\
\hline $\begin{array}{c}\text { Layer } 7 \\
\text { (capping } \\
\text { passes) }\end{array}$ & 13.5 & 240 & 100 & 1225 & 4 & 0.6 \\
\hline \multicolumn{7}{|c|}{$\begin{array}{l}\text { * Automatic Voltage Correction }(A V C) \text { using the RSI. } \\
* * \text { To close the gap at the start, lower current }(100 \mathrm{~A}) \text { was used for } 5-10 \mathrm{~mm} \text { and then } 120 \mathrm{~A} \text { for the rest of } \\
280 \mathrm{~mm} \text { weld length. } \\
* * * \text { Gap was } 2.55 \mathrm{~mm} \text { at the start but } 3.3 \mathrm{~mm} \text { at the endpoint. } \\
* * * * \text { Welding wire was } \varnothing 1.2 \mathrm{~mm} \text { (both normal and hard-facing wires were used in this work). }\end{array}$} \\
\hline
\end{tabular}

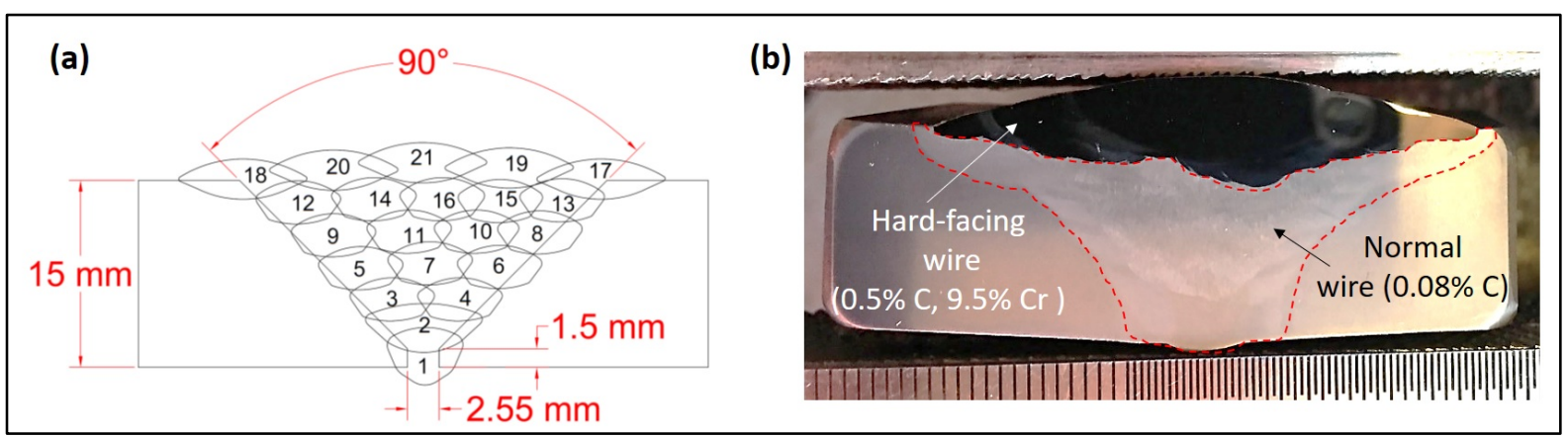

Figure 2. The welding layout (a) and application of both hard-facing and normal wire (b)

In this study, several trials ( $>10$ samples) and main samples were manufactured to test various methods for HIC manufacturing, calibration and also continuous monitoring of HIC (see Table 2). However, the results of the main samples are only reported here and will be discussed in the following sections.

Table 2. Manufacturing methods and samples investigated in this study

\begin{tabular}{|c|c|c|}
\hline Manufacturing method & $\begin{array}{c}\text { Sample } \\
\text { number }\end{array}$ & Purpose \\
\hline Immersed water-quenching & $\# 1$ & \multirow{2}{*}{ Testifying a HIC manufacturing method } \\
\hline Localised water-quenching & $\# 2$ & $\begin{array}{c}\text { Calibration of the continuous monitoring and } \\
\text { robotic inspection system }\end{array}$ \\
\hline $\begin{array}{c}\text { Chemical contamination } \\
\text { halibration sample with side drilled }\end{array}$ & $\# 3$ & $\begin{array}{c}\text { Real-time calibration of the high-temperature } \\
\text { inspection method }\end{array}$ \\
\hline Tungsten embedding & $\# 3$ & $\begin{array}{c}\text { Continuous monitoring of hydrogen crack for four } \\
\text { days }\end{array}$ \\
\hline $\begin{array}{c}\text { Localised water-quenching } \\
\text { (continuous monitoring) }\end{array}$ & $\# 4$ &
\end{tabular}

\subsection{HIC monitoring methodology using robotic welding and inspection system}


[Type here]

Although the HIC is known as the cold crack, the welding thermal cycle and unknown initiation time of crack necessitate an application of a high-temperature inspection system. This is due to the complicated mechanism of the HIC which can be initiated anytime between a few minutes to a few hours after the weld ends. If the welding and NDT stations are separate, it is required to wait until the sample is cooled down, unclamped and then transfer it to the NDT station. The high-temperature inspection is then critical to saving that cooling time, maintain the local stress distributions, and capture the critical moment of the HIC initiation.

To quantify the time required for cooling the weld specimens, a thermocouple is connected to the inspection position ( $17 \mathrm{~mm}$ from the weld centre) and the weld thermal cycle is estimated based on some discrete measurements on the weld surface Figure 3. When the weld temperature is in the range of hot crack, the thermocouple (inspection position) is also recording a temperature higher than the inspection system tolerance $\left(<150{ }^{\circ} \mathrm{C}\right)$. Therefore, the earliest time to start the inspection is about 400 seconds after the weld (point 1 as highlighted in Figure 3) when the weld temperature is about $300{ }^{\circ} \mathrm{C}$ which is assumed not to be late for monitoring of the HIC initiation in this study. This methodology shows the advantage of using the high-temperature in-process inspection developed in this work, against the traditional method to inspect the weld after cooling, because cooling, unclamping and then transferring the sample to the NDT station after the welding can considerably exceed 400 seconds achieved in this study. 


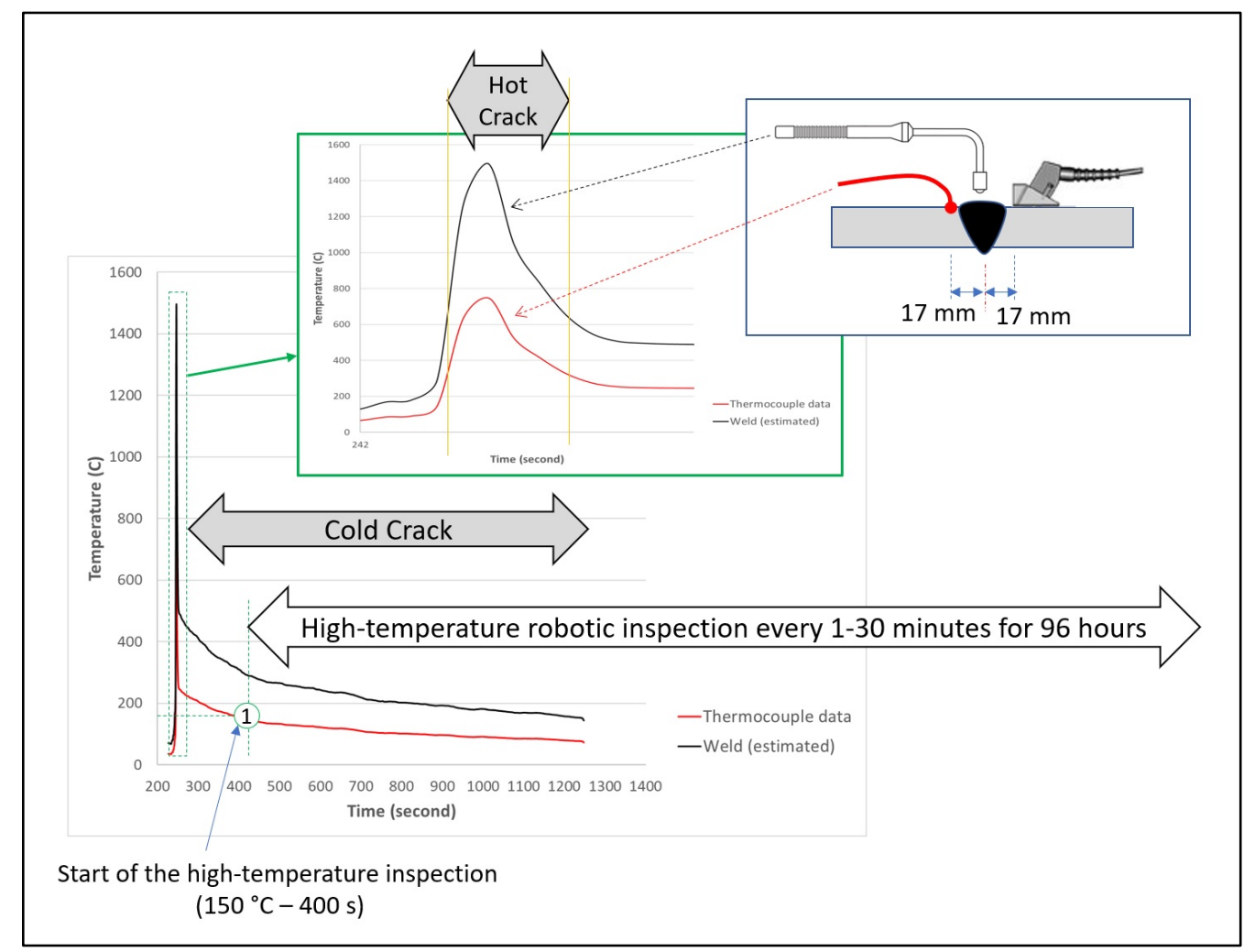

Figure 3. The necessity of using the high-temperature ultrasonic system for the HIC monitoring

Since conventional ultrasonic NDT is limited to operation at temperatures up to 50 degrees C, a high-temperature approach is demanded. Using high-temperature couplant (Olympus hightemperature ultrasonic gel) and wedges (Olympus ULTEM wedge), the temperature of operation can be extended to up to $150^{\circ} \mathrm{C}$. However careful monitoring of the temperature is required to prevent degradation of the transduction materials and process. Hence the requirement for the thermocouples, additional control, and the repeatable robot positioning used in the high-temperature in-process inspection is justified. The automated multi-pass welding and inspection system used in this study is shown in Figure 4. The Tungsten Inert Gas (TIG) welding process is deployed via a 6-axis KUKA robotic manipulator equipped with a TIG welding torch. The inspection process utilizes a separate 6-axis KUKA robot to deploy an NDE end-effector carrying a Phased Array Ultrasonic (PAUT) array and angled wedge for shear wave inspection. The NDE end-effector has three main parts: (I) ultrasonic array, (II) high-temperature compliant wedge and (III) thermocouples. The ultrasonic array is a $5 \mathrm{MHz}, 64$ elements, $0.5 \mathrm{~mm}$ pitch array. The angled wedge (giving shear waves centred around $55^{\circ}$ ) is manufactured in an amorphous thermoplastic polyetherimide resin called $\mathrm{ULTEM}^{\mathrm{TM}}$ and is capable of withstanding intermittent temperatures as high as $150^{\circ} \mathrm{C}$. The 
[Type here]

wedge holder was also equipped with four spring-loaded thermocouples which first touch the specimen, before the wedge, to ensure the surface temperature is less than the wedge operational limit. High-temperature couplant is utilized between the wedge and the surface under inspection. A Peak NDT LTPA phased array controller was used for array control and signal acquisition with an active aperture of 64 elements. A National Instruments, Compact RIO 9038 real-time controller programmed in the LabVIEW environment, is employed to control the TIG welding machine, welding robot, inspection robot, thermocouples and PAUT controller.

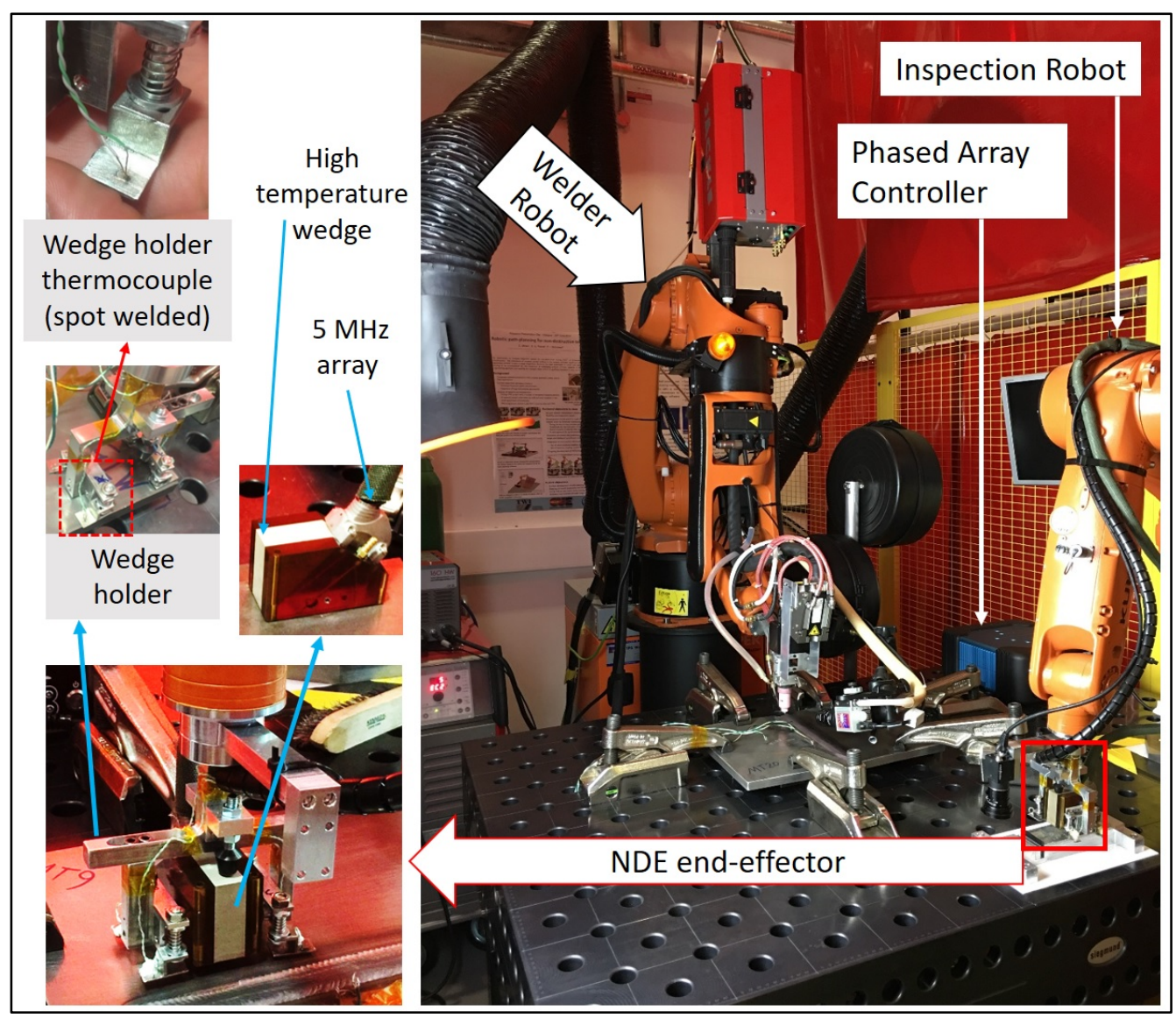

Figure 4. Automated multi-pass welding and inspection system

The process first starts with the autonomous deposition of a welding pass by the welder robot, defined by the material, thickness and groove preparation. Permanent thermocouples attached to the specimen plate being welded monitor the surface temperature for overall process control purposes. After the completion of a single welding pass and the specimen surface temperature drops to $150^{\circ} \mathrm{C}$, the inspection robot initiates the NDE process. 
The inspection robot first introduces sufficient couplant to the wedge lower surface by bathing it in a couplant bath built for the purpose. The NDE end-effector is then deployed at multiple user-defined scanning positions along the welding axis. The four thermocouples attached to the NDE end-effector first contact the sample surface and verify that the temperature is below the $150{ }^{\circ} \mathrm{C}$ limit. If so, the end-effector is deployed downward and the wedge and couplant make contact with the surface specimen. The chosen array processing technique (FMC and/or Sectorial Scanning) is then generated and received data captured by the PA controller. The NDE process is repeated for each subsequent scanning position along the weld axis.

\subsection{Immersed water-quenching sample (Sample\#1)}

As the hydrogen (and then water) is believed to be the main reason for the hydrogen cracks, an experiment was run on a multi-pass sample which was quenched after the welding passes (water spraying all over all passes until Pass 11 and then after each layer). The sample was then left in the water tank (fully immersed water-quenching) for sixty hours (Figure 5). It is worth mentioning that the weld was fully deposited using the hard-facing wire. The sample was then tested by both time-of-flight diffraction (TOFD) and phased array sector scanning methods to detect the defects and mark important cross-sections for the metallography. The sample was sent for the water-jet cutting and metallography investigations, see Figure 5, to verify the ultrasonic results and testify the intentionally-manufactured defect.

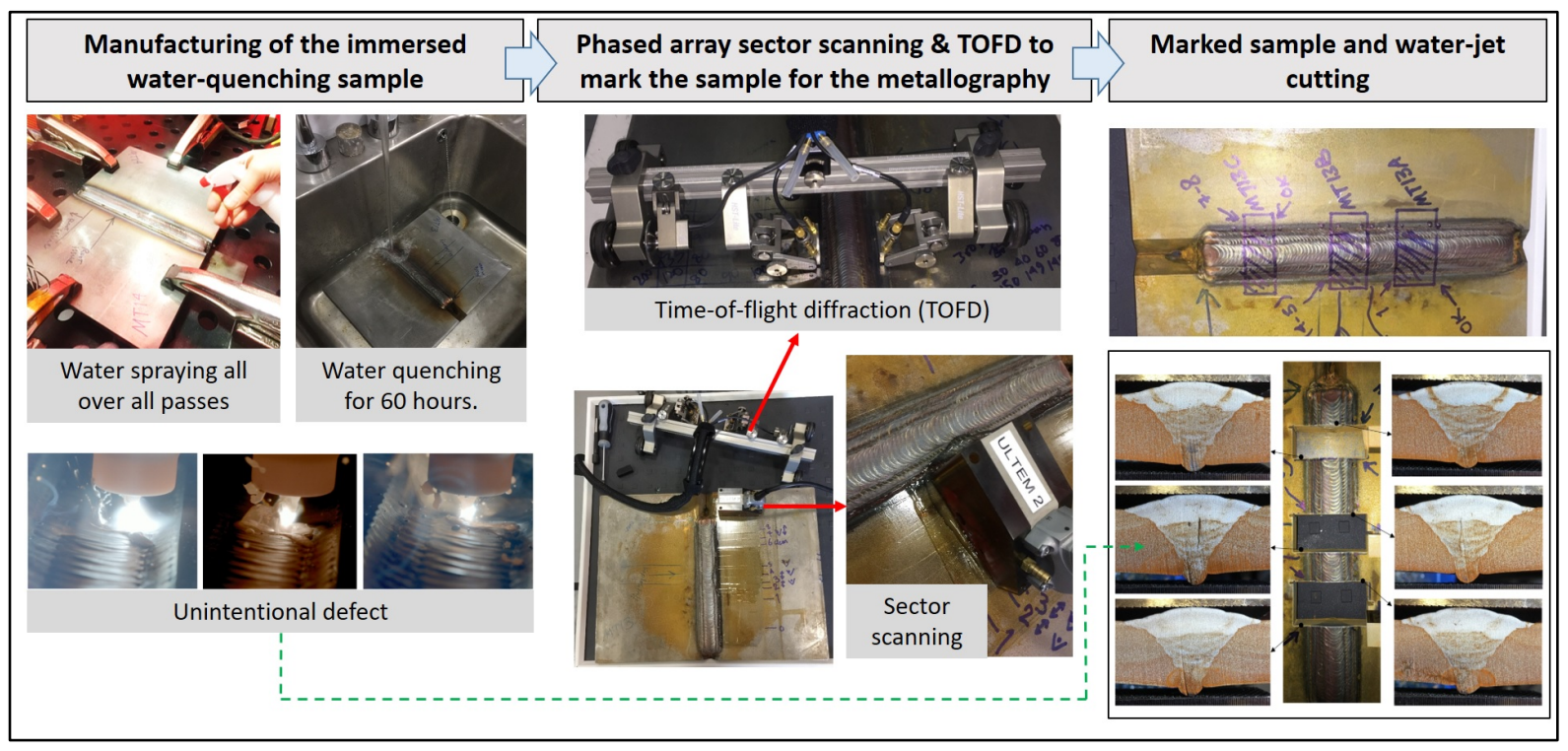

Figure 5. Immersed water-quenching sample (Sample\#1): manufacturing, NDT and metallography preparations 
[Type here]

As shown in Figure 5, an unintentional defect happened during the welding of Pass 11. This was an unexpected burst in the weld pool which stopped the welding process, therefore, an undesired stop/start point was produced in the centre of the weld length. It is believed that the reason for this burst was an excessive amount of hydrogen trapped inside the weld and then very high pressure released following the vaporisation and bubbling during the completion of Pass 11 . Not only this burst made some visual spattering defects over the weld surface but also it was the reason for a large crack (see the weld middle sections of the water-jet cut sample in Figure 5) which will be discussed later.

\subsection{Localised water-quenched \& Chemical contaminated sample (Sample\#2)}

As shown in Figure 1, there is a combination of factors participating in the HIC process. It is believed that the combination of water quenching and stress can encourage the HIC more than the application of single factor (just water as used in Sec. 3.3). This is based on the knowledge of welding residual stress which is a localised procedure too and then any localised shock is expected to produce a higher amount of the residual stress. Therefore, a localised water-quenched sample was manufactured (see Figure 6) to encourage the HIC in a section match to the NDT position 3. It is worth mentioning that the weld was fully deposited using the hard-facing wire. Thermal insulation is used to avoid water reaching other sections of the weld other than the targeted localised section. Since any contamination can potentially result in the HIC, the high-temperature ultrasonic couplant (Olympus Couplant H-2 temperatures up to $398^{\circ} \mathrm{C}$ ) was applied as chemical contamination on the Pass 7 surface. This was also a localised section ( $<20 \mathrm{~mm}$ length) to testify various HIC manufacturing methods. The sample is then marked, for the subsequent metallography, using phased-array inspection and TOFD. Two large cracks are visible in the localised water quenched section (see Figure 6) and will be discussed in the future sections. There is no crack visible in the water-jet cut section of the chemically contaminated area, however, a further polishing, etching (metallography) and microscopic investigation will be carried out to study the couplant effect accurately. 


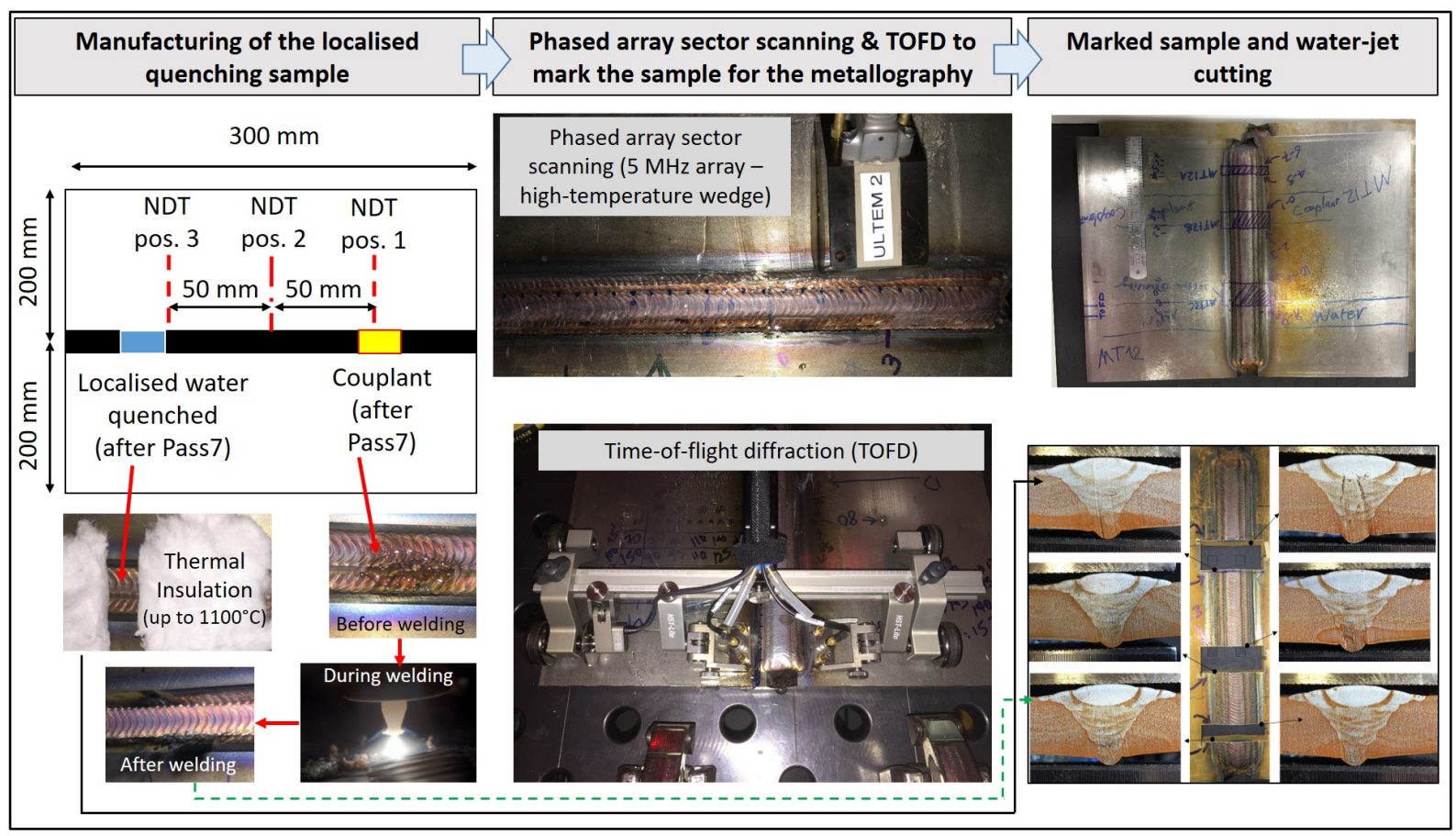

Figure 6. Localised water-quenched and chemical contaminated sample (Sample\#2): manufacturing, NDT and metallography preparations

\subsection{Continuous monitoring of the calibration sample (Sample\#3)}

During the continuous monitoring trials, some variations were observed in the reflection amplitude from the same feature. Therefore, it is necessary to calibrate the continuous inspection system using a reference sample. The reference sample was cut from a sample with the same manufacturing parameters and two $\varnothing 2 \mathrm{~mm}$ side drilled hole (SDH) were manufactured in the weld (see Figure 7). Due to the very high hardness of the weld (deposited with the hard-facing wire), manufacturing SDH with smaller diameter was impractical. The reference sample was tested in the same experimental setups used for the high-temperature inspection of the main sample with the HIC. 


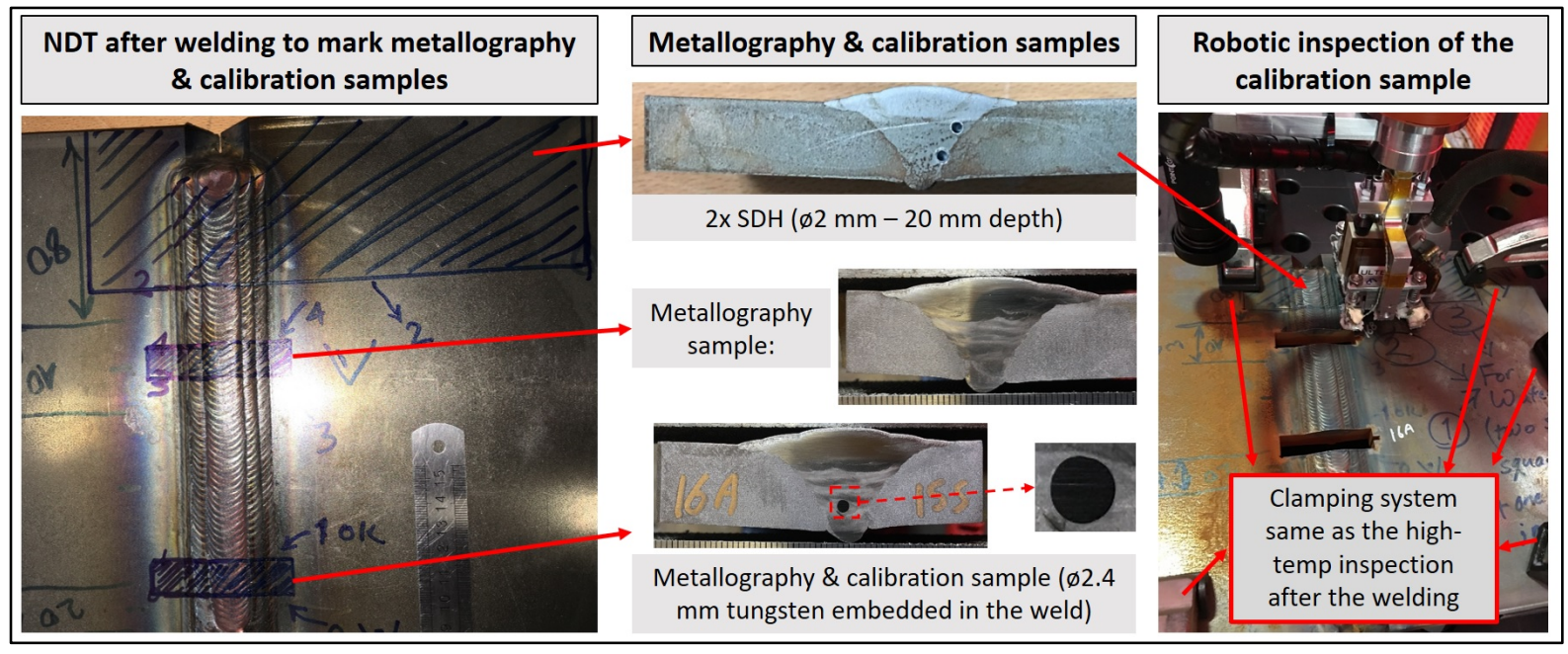

Figure 7. NDT, metallography, calibration and continuous monitoring of the calibration sample (Sample\#3)

In this study, various samples were manufactured with different types of intentional weld defects (see Table 2). Several methods (like chemical contamination, localised or immersed water quenching) were tested to manufacture HIC, however, tungsten embedding method was also used for calibration (see Figure 7). In this method, a tungsten rod (ø2.4 mm) is intentionally embedded in a ground slot on the weld surface to be covered by the subsequent pass. Since the tungsten rod is a known size defect and is embedded in a known location of the weld, it can be used for real-time calibration of the high-temperature inspection method used in this study. The tungsten embedding process was introduced by Javadi et al [12] who used tungsten rod and balls in a buttering and welding process. They subsequently used PAUT and TFM to detect the position of these tungsten inclusions however the method was not accurate enough to be used for the calibration of the NDT system. Javadi et al [21] studied the tungsten embedding process in a Wire + Arc Additive Manufacturing (WAAM) sample. They detected the tungsten balls and used them to calibrate their PAUT inspection system to detect and size an unknown size lack of fusion. The same approach is therefore used in this study to verify the performance of the high-temperature inspection system, i.e., whether the NDT system developed here is enough accurate to detect the tungsten during a high-temperature inspection.

\subsection{Continuous monitoring of the HIC sample (Sample\#4)}

A sample with hard-facing wire was manufactured and the localised water-quenching process was applied after the last pass in the NDT position 3 (see Figure 8). The sample was then 
inspected for 96 hours by the high-temperature inspection system using the phased array sector scanning setup. The scanning intervals were 1 minute at the start but it was increased to 30 minutes, after 1.5 hours, to reduce the amount of data captured over four days. The sample was then unclamped for subsequent water-jet cutting and metallography for NDE comparison purposes.

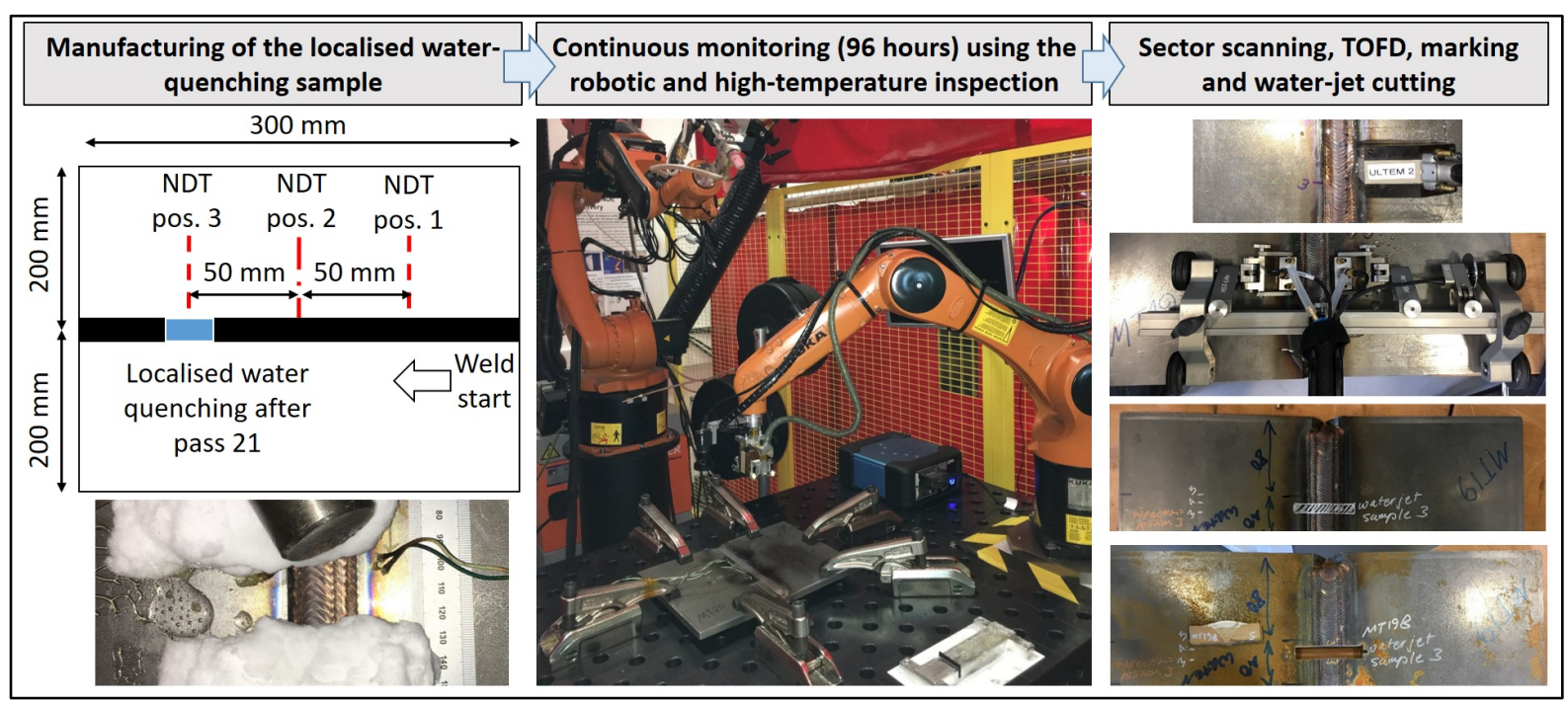

Figure 8. Continuous monitoring of the HIC sample (Sample\#4)

\section{Results and discussions}

\subsection{Intentionally-induced hydrogen crack in a multi-pass weld}

The macrograph and microscopic investigations of the localised water quenching sample (Sample\#2) are shown in Figure 9 which proves that two large cracks are successfully manufactured in the weld. TOFD was used to measure the crack length in the weld length direction (see Figure 9b). 
[Type here]

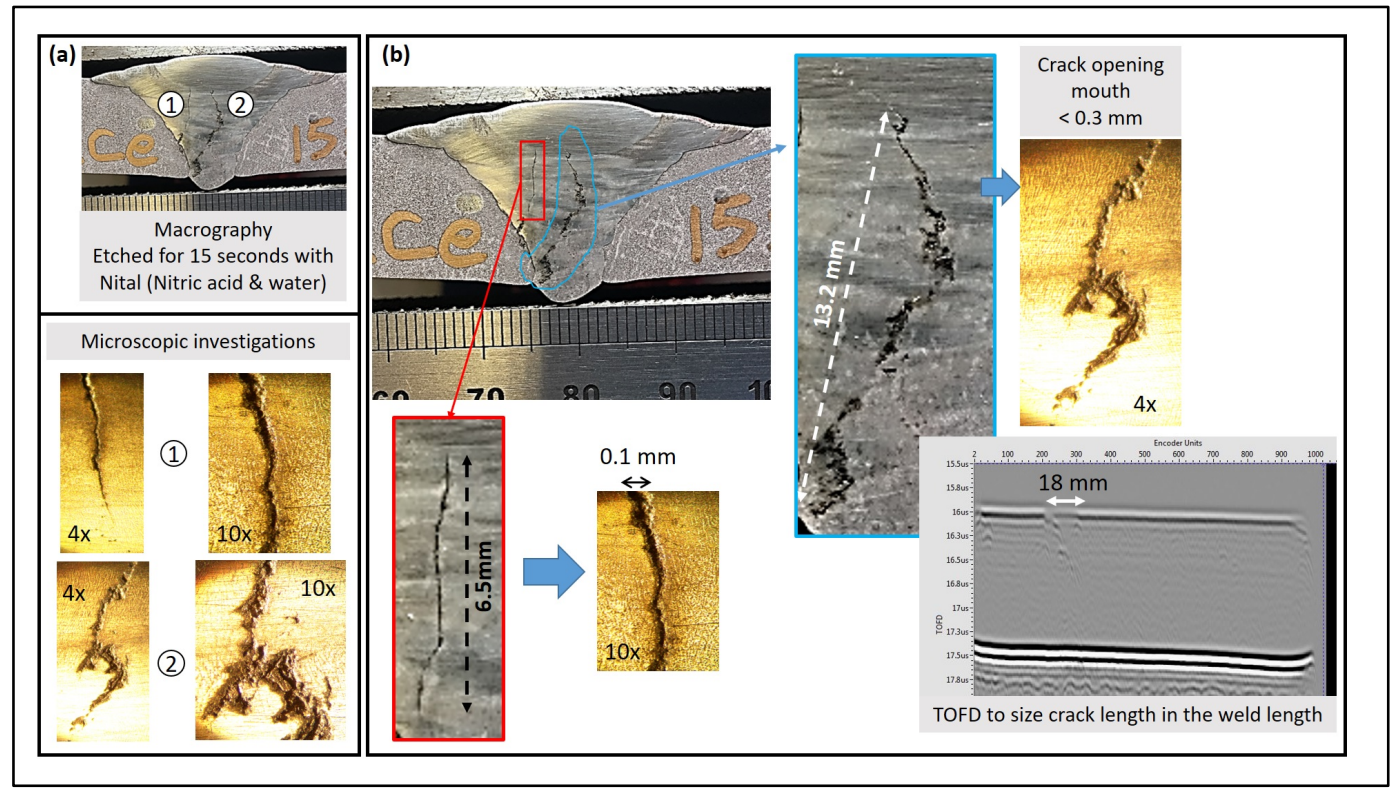

Figure 9. Macrograph and microscopic investigations (a) and crack dimensions measurement (b) of the localised quenched sample (Sample\#2)

It is believed that both cracks shown in Figure 9 are hydrogen crack because the cracks are exactly (and only) in the localised water quenched section while the rest of the weld is defectfree (see Figure 10). The sample was first tested by both phased array sector scanning and TOFD systems to decide which sections are required to be cut for the subsequent macrograph and microscopic investigations (see Figure 10).

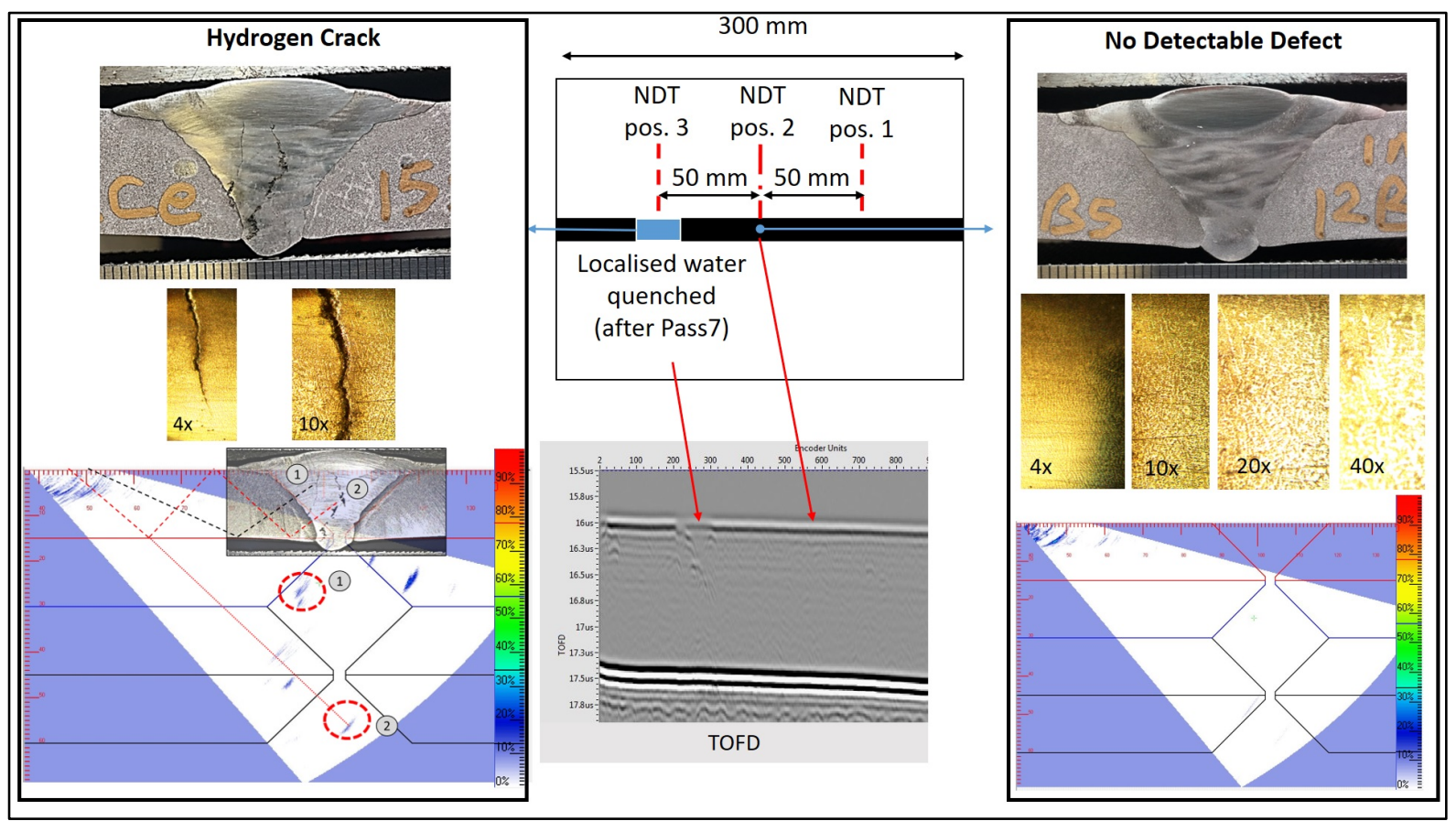

Figure 10. Macrograph, microscopic, phased array sector scanning and TOFD comparison between the HIC and defect-free sections (Sample\#2) 
The localised chemical contamination with the high-temperature couplant, testified on Sample\#2, was not a solution for HIC manufacturing as it only resulted in porosities as shown in Figure 11. To verify this intentional porosity manufacturing process, the couplant applied on several samples and two of them are shown in Figure 11. It can be concluded that the chemical contamination, using the material used in this study (i.e., high-temperature ultrasonic couplant), cannot result in HIC but a controllable porosity in the weld. This porosity was only observed in the contaminated section and then there is a good control on all three dimensions (only detected after the specific pass on which the couplant was applied).

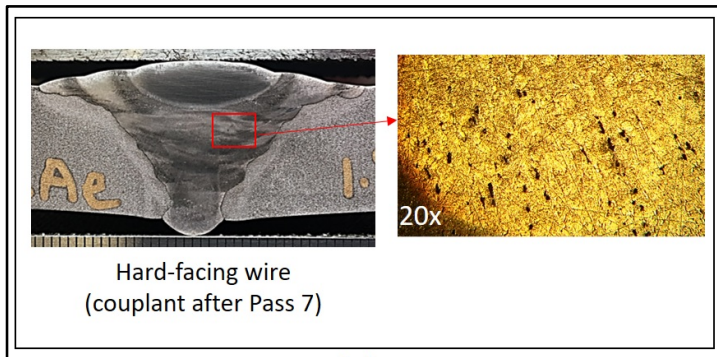

(a)

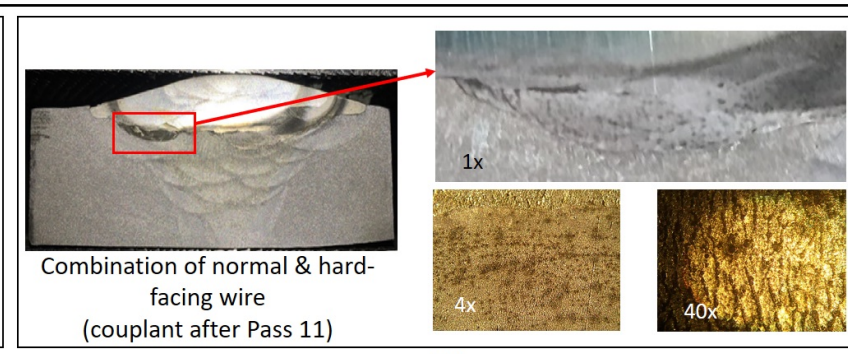

(b)

Figure 11. The effect of chemical contamination (Sample\#2) on the weld porosity using high-temperature couplant applied after pass 7 (a) and pass 11 (b)

The macrograph and microscopic investigations on the immersed water-quenched sample (Sample\#1) are shown in Figure 11. The fully-quenching process has resulted in manufacturing many porosities rather than HIC. The porosity observed in the immersed sample (Sample\#1) looks much larger than those produced by the chemical contamination method (Sample\#2) however the latter is a controllable process which can produce the porosity in a specific pass number with a predetermined position.

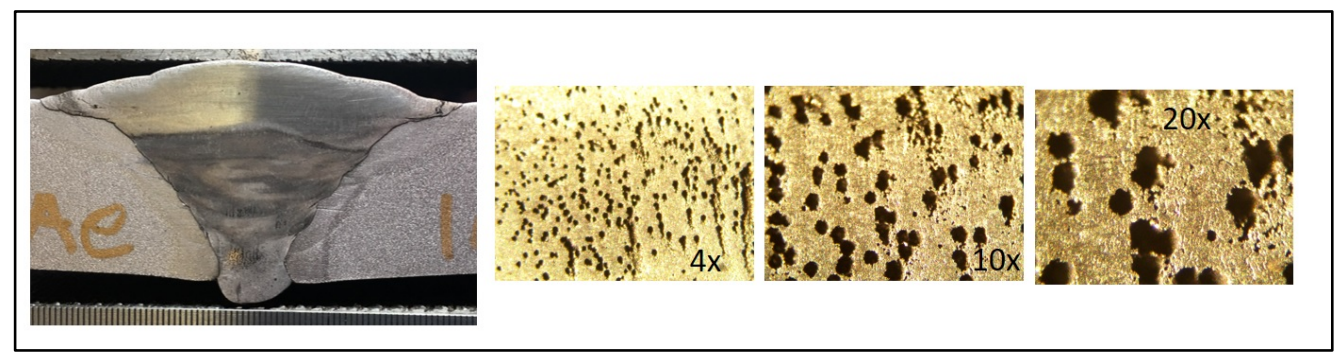

Figure 12. Macrograph and microscopic investigations on the immersed water-quenched sample (Sample\#1) 
[Type here]

There is also a crack detected in the immersed quenching sample (Sample\#1 as shown in Figure 13) in the same position in which an unintentional defect was produced due to the burst in the weld pool (as shown in Figure 5). The crack had been detected by both phased array sector scanning and TOFD (implemented on both top and bottom surface of the plate) before the water-jet cutting and metallography.

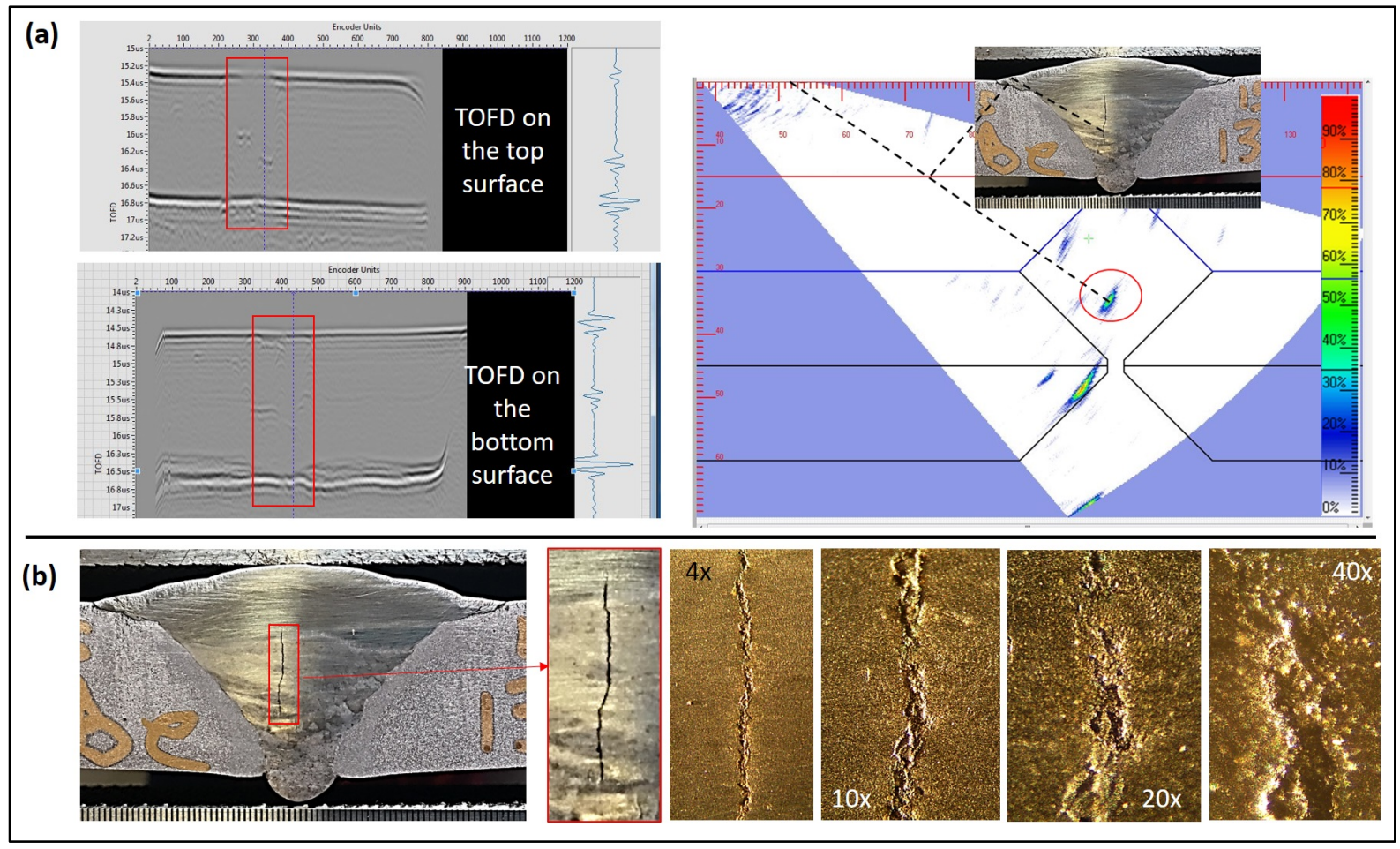

Figure 13. TOFD and phased array scanning (a) and metallography results (b) of the unintentional defect (crack) manufactured in the immersed water-quenched sample (Sample\#1)

Although this crack has happened in a sample quenched by the water, it is believed that this is not a hydrogen crack. This can be proved by comparison with the hydrogen crack manufactured in the localised quenching sample (Sample\#2). The immersed quenching sample (Sample\#1) crack is a straight crack perpendicular to the maximum stress plane (clamping forces) while the localised quenching sample (Sample\#2) crack has a random shape and is initiated from the pass on which the water was sprayed. This latter is more close to the morphology of hydrogen crack while the first is like a stress crack produced due to the mechanical shock of the burst in the weld pool. The mechanical shock was an add-up to the thermo-mechanical shock of the water quenching along with the start and stop point shock. 
Therefore, all of these unintentional thermal, mechanical and process shocks were the reason for the crack in the immersed quenching sample (Sample\#1). It should be noticed that if that unintentional burst had not happened in a specific point, it was not any guarantee for the crack to be initiated as it has not happened in any other sections of the weld except than the start and stop point. Alternatively, the localised quenching method (used on Sample\#2 and Sample\#4) has been tested on $>10$ samples and the HIC has been detected in all of them in the expected location.

Regardless of the above discussion, the nature of crack in Sample\#1 is hard to determine and then there is still a possibility that this crack is a hydrogen crack. However, it is worth mentioning that even if the immersed quenching sample (Sample\#1) crack was a hydrogen crack, this could not be of the interest of this paper in which a controllable manufacturing process is required. This controllable process is mandatory because if the location of the crack (in the weld length) is random, like the immersed quenching sample (Sample\#1), it is impractical to implement continuous monitoring for four days on all over the weld length. Therefore, the localised quenching sample (Sample\#2) is preferred in this paper because a reliable and repeatable HIC manufacturing method is critical for the subsequent continuous monitoring.

To verify the reproducibility of the HIC, ten samples were manufactured using the localised quenching procedure and the results are shown in Figure 14. This is a repeatable process and the HIC can be manufactured in any specific weld length and position. This repeatability was crucial for the NDT system and it can be considered as a successful development because the HIC was always detectable in a predicted NDT position, i.e., NDT position 3 as shown in Figure 14. Due to the complex mechanism and random growth-path of the HIC, it is not possible to exactly predict from which weld pass number (s) the crack will pass. However, the crack was always initiated in the predicted weld layer (the last deposited layer before quenching). Furthermore, the existence of HIC was very important in this paper because not all the intentionally-embedded defect methods can result in producing an expected defect and several unsuccessful methods have been reviewed by Javadi et al [8]. This can be even more challenging when the expected defect is a tiny crack like the HIC. Therefore, if the HIC had not been produced even in one of the ten samples studied in this work (or produced somewhere out of the predetermined NDT position), the localised quenching method could not be selected for the verification of the NDT development considered in this paper. 
[Type here]

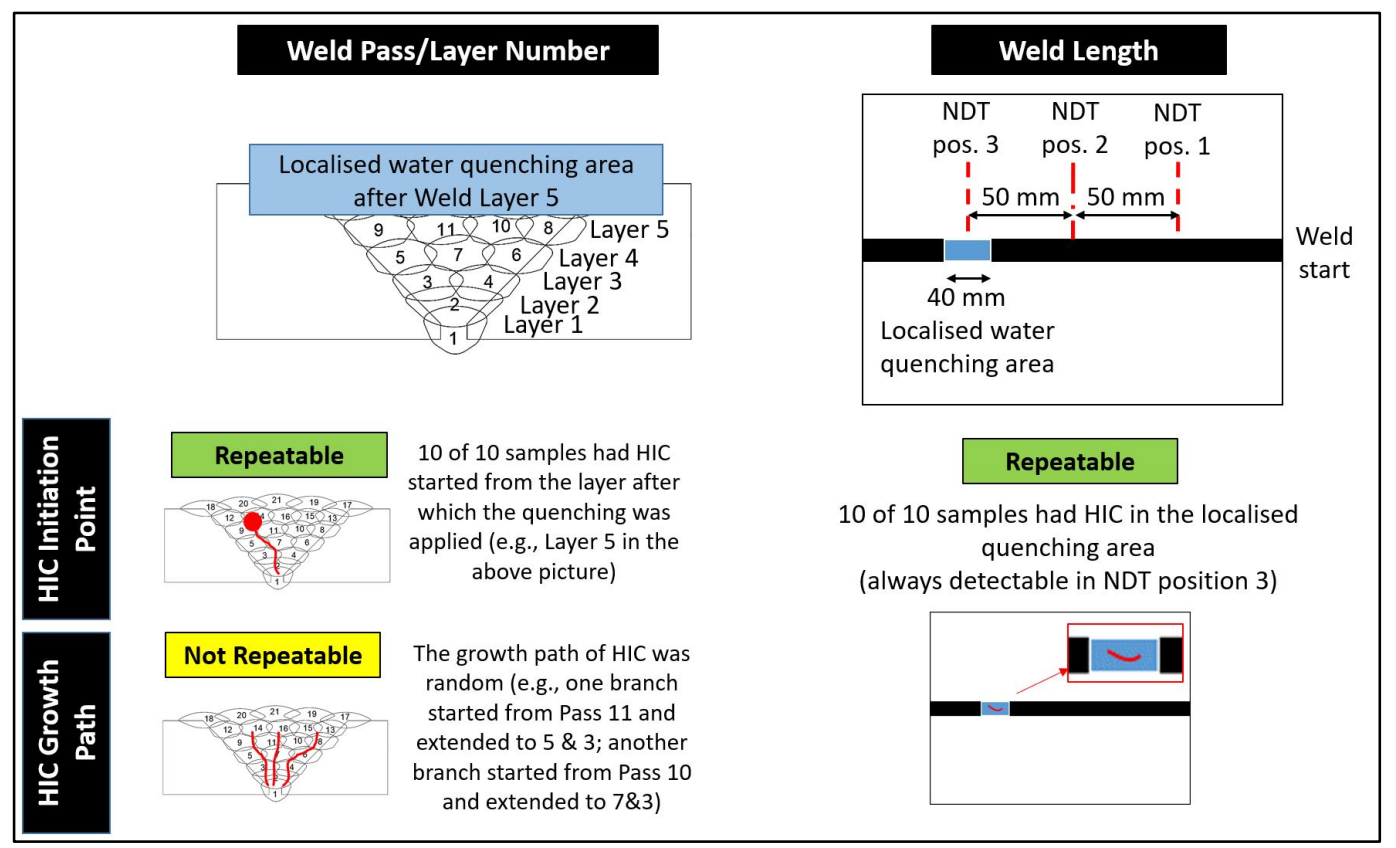

Figure 14. Repeatability of HIC manufacturing using the localised quenching method

\subsection{Continuous monitoring of the reference sample (Sample\#3)}

The continuous monitoring system needs to be calibrated first and then the setup shown in Figure 7 was used with the results shown in Figure 15. The dB-scale colour-bar of the sector scans is set based on a traditional NDT rule to set the screen for the A-scan on $80 \%$ of the maximum of the vertical axis (reflection amplitude). This is to ensure that none of the sector scans, during the 96 hours continuous scanning, will be captured with a saturated gain ( $>100 \%$ of the A-scan screen) and then they are comparable (see Figure 15). The same methodology and phased array setup will also be used for the continuous monitoring of the HIC. As shown in Figure 7, a tungsten embedded defect was also used for the calibration. This was mandatory for calibration of the high-temperature scanning to compensate for the temperature effect using a known-size defect which was embedded in a known location of the weld. 


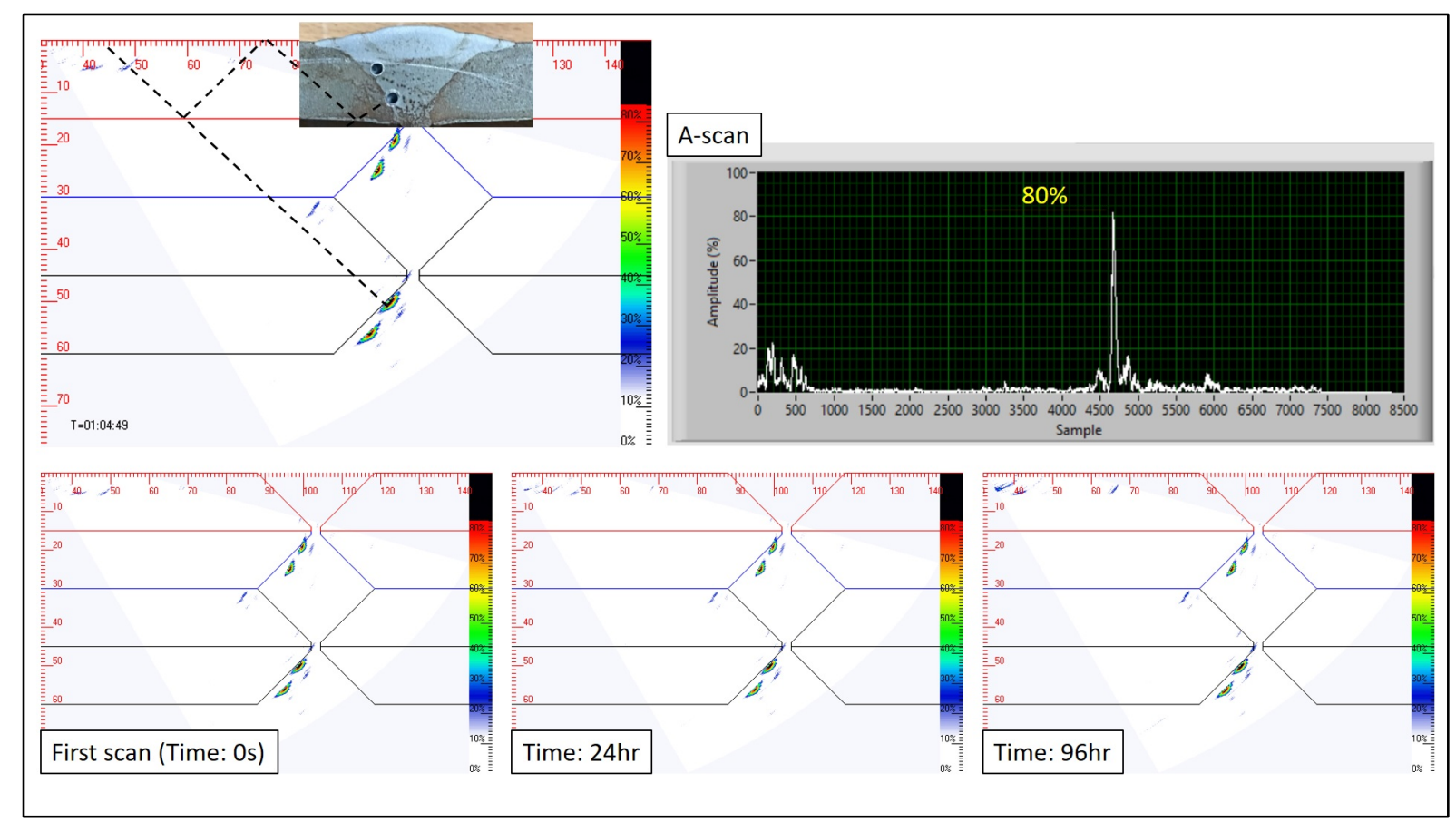

Figure 15. Continuous monitoring of the calibration sample with SDH (Sample\#3)

\subsection{Summary of the intentional weld defect process}

The results achieved for various intentional weld defect processes testified in this study (introduced in Table 2) are summarised in Figure 16. Although the target was the manufacturing of a HIC defect, only the localised water quenching method implemented in Sample\#2 reached this goal. The immersed quenching sample (Sample\#1) was achieved in the porosity but, since all over the weld is quenched, neither pass number nor the specific weld length location is predictable. This sample has also resulted in an unintentional weld defect (crack) but with a completely random (and not repeatable) manufacturing process. The crack was in a specific weld length location but the pass number was not controllable and the process is not repeatable, therefore, that specific position is hard to achieve again. The chemical contamination process (Sample\#2) also resulted in a repeatable manufacturing process of porosity in very controllable (both weld length location and the exact pass number) position. The tungsten embedding process (Sample\#3) was found the most controllable and accurate intentional weld defect process and then it was used for calibration as it is a known size defect in a specific position of the weld length/pass and fully repeatable process. 
[Type here]

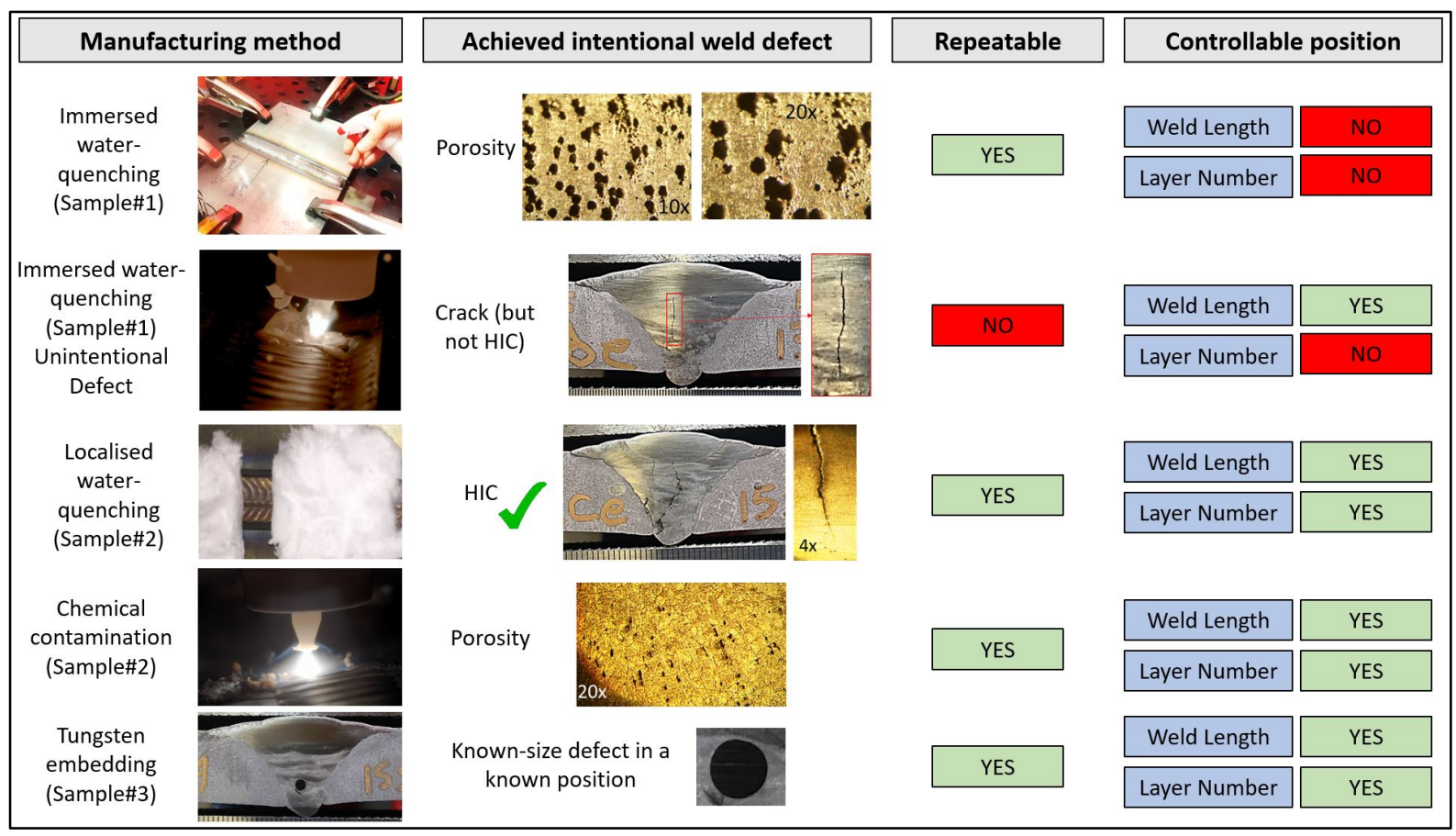

Figure 16. Summary of the intentional weld defects manufactured in this study (target: HIC)

\subsection{Continuous monitoring of HIC sample (Sample\#4)}

Since the localised quenching method (Sample\#2) was proved to be the only reliable and repeatable HIC manufacturing technique used in this study, another sample (Sample\#4) was manufactured in which quenching was applied on a location equivalent to the NDT position 3 (Figure 8). This sample was monitored for 96 hours and an overview of the results is shown in Figure 17. It has been shown that only in the NDT Position 3, which was water quenched, there is a reflector changing during the time. Therefore, the system has successfully monitored a hydrogen crack. 


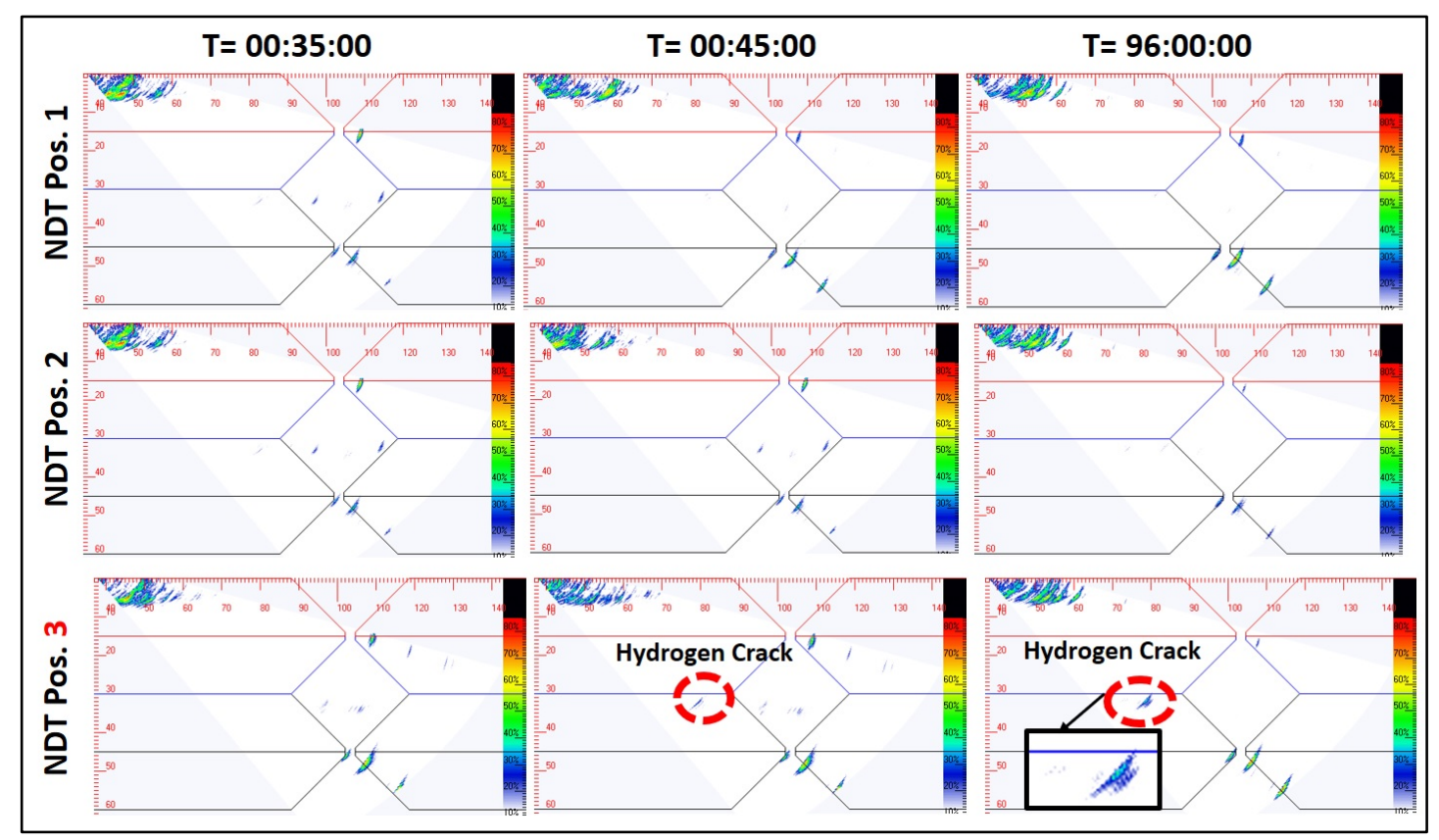

Figure 17. Sector scanning comparison between three inspection positions (hydrogen crack was expected in the NDT Position 3 due to the localised water quenching)

The only available consistent feature in the sector scan, the ultrasonic wave reflection amplitude from the root pass, is considered (Figure 18) to monitor the HIC quantitatively. This is expectably a known reflector and then it is supposed to show the same reflection amplitude over the time and in all sector scans captured within four days. Therefore, this was set to $80 \%$ to ensure that the variations would not exceed than the $100 \%$ (saturated gain). It is now possible to measure the reflection amplitude of the HIC, for example, it is $43 \%$ at the moment shown in Figure 18.

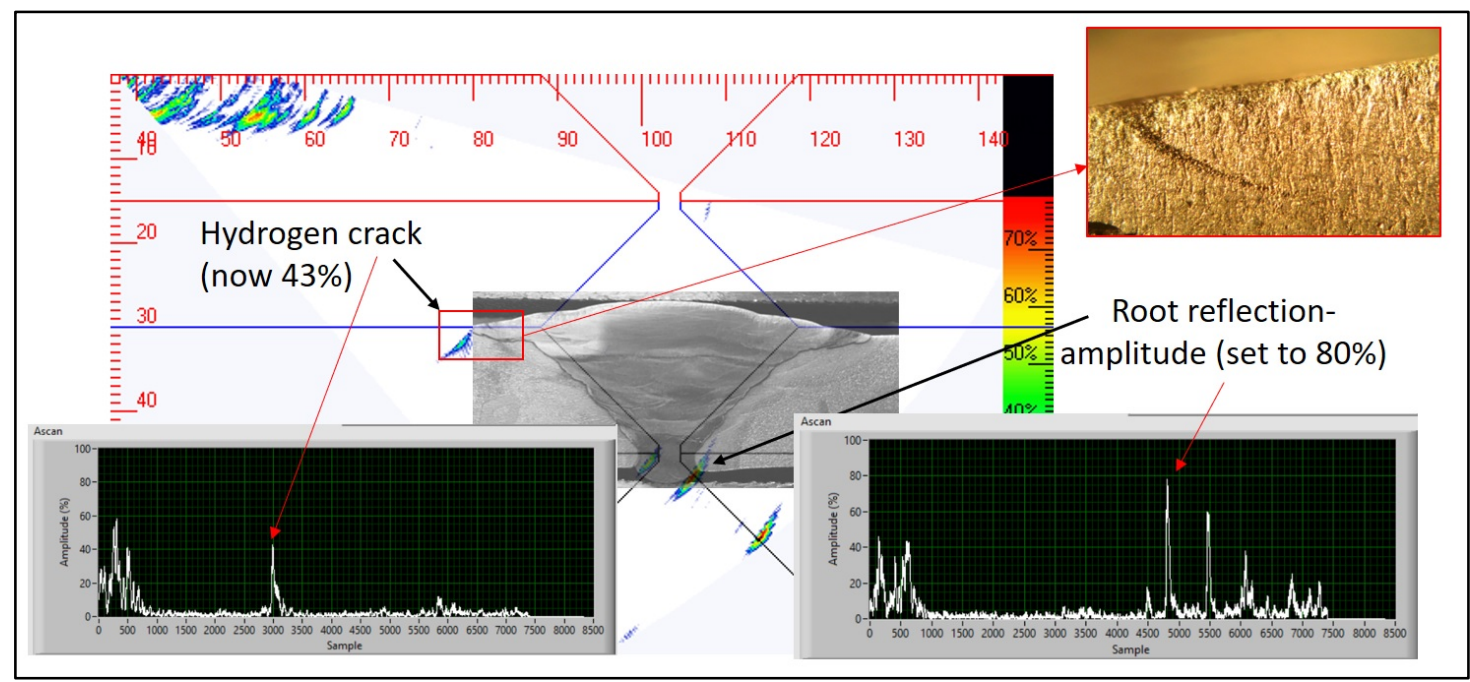

Figure 18. Quantitative investigation of the HIC using the reflection amplitude of crack and root 
[Type here]

The first-hour monitoring results are shown in Figure 19. This shows that the hydrogen crack was initiated 43 minutes after the weld ended, and grown very fast for 10-15 minutes. From the root reflection amplitude (RRA), a fluctuation around $10 \%$ is observed which can be considered as the measurement error due to the wedge orientation slightly change in each contact for the scanning. This error had been already assessed and calibrated using the continuous monitoring of the calibration sample (Sec. 4.2). Therefore, the ratio of HCRA/RRA is a normalised number which can distinguish the HIC variations from the system error (see Figure 20). This shows that the HIC has continued to grow for 24 hours after the weld but there are no considerable variations in the reflection amplitude between 24 to 96 hours.

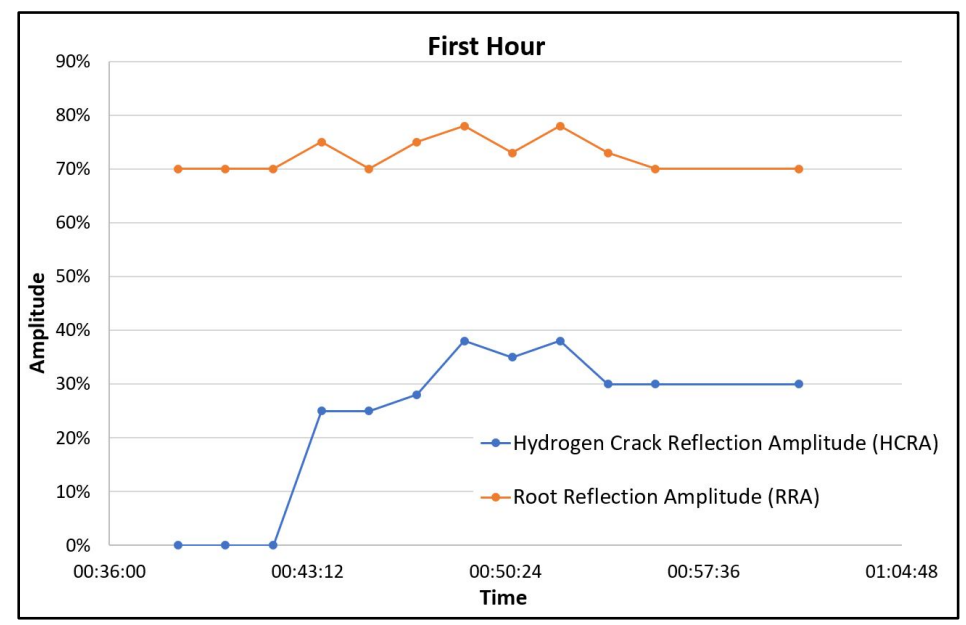

Figure 19. First-hour monitoring of the HIC

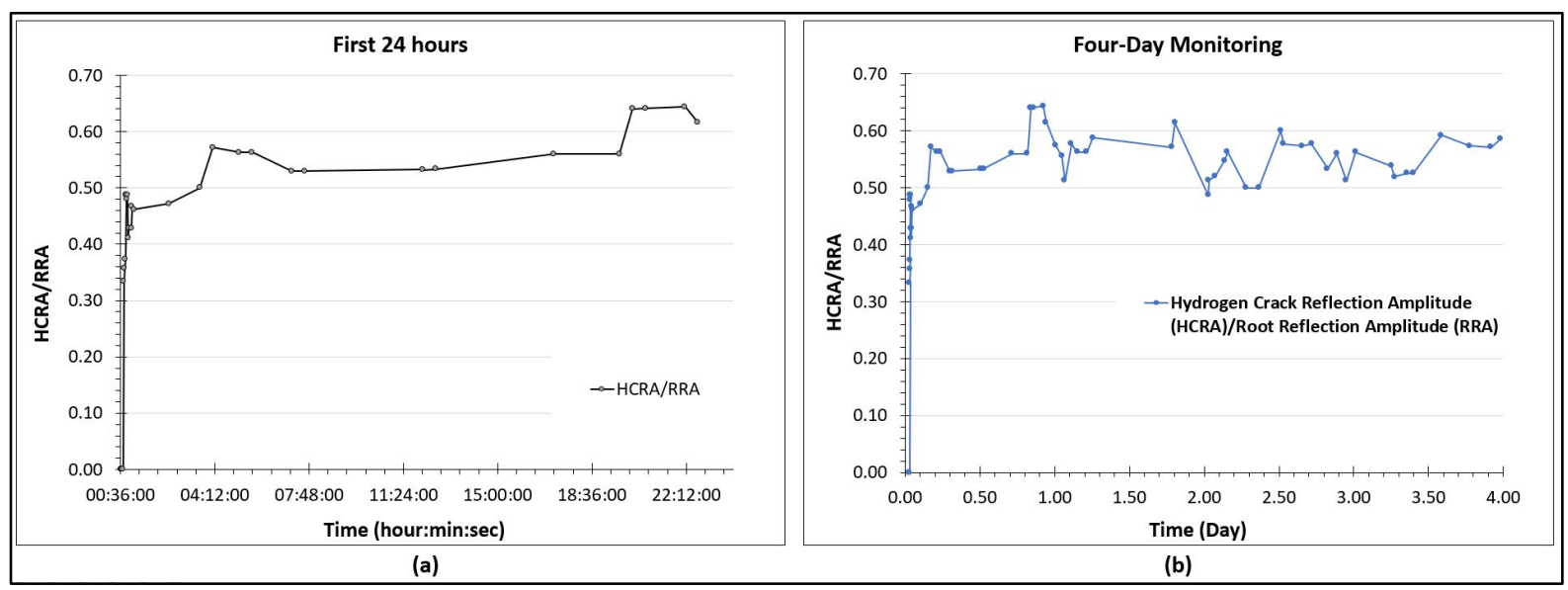

Figure 20. HCRA/RRA ratio to monitor the hydrogen crack over 24 hours (a) and four days (b) 


\section{Conclusions}

A combination of robotic multi-pass welding and automated phased array inspection is successfully implemented in this work to monitor hydrogen crack during a four-day phased array inspection. For calibration purposes, a sample with side drilled holes was inspected continuously. Based on the achieved results, it can be concluded that:

1) A controllable and reliable method of HIC manufacturing was successfully developed which includes deposition of hard-facing wire and a localised quenching process. Manufacturing of the HIC in the expected position was then verified by the macrograph and microscopic investigations.

2) This study confirmed that the hydrogen cracks mechanism is a complicated process and then the expected effecting parameters (e.g., fully water-quenched procedure) can manufacture a sample less prone to the hydrogen cracking in comparison with the localised quenched sample. The fully-quenched sample resulted in the porosity but not a HIC.

3) There is an exception with the immersed quenching sample in which a crack was detected in place having an unexpected process issue. Although this was a large crack, the manufacturing method was not considered in this study for continuous monitoring because it was not a repeatable manufacturing process.

4) Application of high-temperature couplant as the chemical contamination was also tested but only porosity was visible in the contaminated area. However, this can be considered as a repeatable method for manufacturing the porosity in an exact and predetermined position (specific weld pass in the exact location of the weld length). It should be noted that only one material (Olympus high-temperature ultrasonic couplant gel) was tested as the chemical contaminating material and it did not result in any HIC. This part was a limited experimental study and cannot rule out the known effect of chemical contamination on the HIC.

5) The reproducibility of the hydrogen crack using the localised water quenching method was studied and it was found that the HIC can be repeatably manufactured in any specific weld length and position. This repeatability was crucial in this work because the localised quenching method is used for the verification of the NDT development.

6) The reference sample with SDH was continuously monitored to calibrate the continuous monitoring system. 
[Type here]

7) The HIC sample was successfully monitored for four days. An innovative robotic NDT system was used to monitor a weld sample immediately after the welding, using a new development of high-temperature in-process inspection, followed by a longterm (96 hours) inspection using phased array ultrasonic testing. The timing was designed to (I) include high-temperature in-process inspection, ensuring that the detection of HIC is not missed due to a lag time between manufacturing and inspection, and (II) covers the 16-96 hours rule which is the time stated in the standards as the waiting time for the inspection of HIC.

8) As expected, from the innovative and reliable manufacturing method which was developed in this work, the HIC repeatably occurred in the expected position (the area of localised water quenching) on which another innovative system (high-temperature in-process inspection) had been set up to ensure neither the initiation nor the growth of the HIC will not be missed. Based on the permanently available results of the robotic NDT system, the HIC was initiated 43 minutes after the weld ended, grew rapidly for about 15 minutes (45-60 minutes after the weld) and continued growing for around 24 hours. However, no considerable growth was detected between 24 to 96 hours.

9) The standard rule of 16-96 hours delay between the NDT and welding end time was validated using the robotic NDT mechanism developed in this paper. Because no considerable HIC growth was detected between 24 to 96 hours after the weld ends, it can be concluded that the rule is applicable in this work. However, it was found that an automated high-temperature inspection system can ensure the reproducibility required to validate that standard rule.

\section{Acknowledgements}

This work was undertaken as part of the UK Research Centre in NDE (RCNDE EP/L022125/1) core project (ABC of ARC) and also RCNDE3 core research Feasibility Project (entitled "Test Samples to Support Developments in High-Temperature In-Process Inspection"). Furthermore, the concept of in-process inspection will be used in the Wire + Arc Additive Manufacturing (WAAM) projects which are all supported by EPSRC and InnovateUK as follows: (I) NEWAM (EP/R027218/1), (II) AIMaReM (EP/N018427/1) and (III) RoboWAAM (EP/P030165/1). The authors then like to acknowledge EPSRC, 
InnovateUK and RCNDE for the support and funding of the projects. The authors also like to acknowledge Mr Grant Smillie for macrograph, Mr George Cochrane and Mr Alex Ward for machining.

\section{References}

[1] N. Bailey, F.R. Coe, T.G. Gooch, P.H.M. Hart, N. Jenkins, R.J. Pargeter, Chapter 1 Defining the problem, in: N. Bailey, F.R. Coe, T.G. Gooch, P.H.M. Hart, N. Jenkins, R.J. Pargeter (Eds.), Welding Steels Without Hydrogen Cracking (Second Edition), Woodhead Publishing2004, pp. 1-16.

[2] L. Vergani, C. Colombo, G. Gobbi, F.M. Bolzoni, G. Fumagalli, Hydrogen Effect on Fatigue Behavior of a Quenched\&tempered Steel, Procedia Engineering 74 (2014) 468-471.

[3] J.C. Lippold, Hydrogen-Induced Cracking, Welding Metallurgy and Weldability 2014. [4] B. STANDARD, Welding - Recommendations for welding of metallic materials, Part 2: Arc welding of ferritic steels, BSI Group, UK, 2009.

[5] P. Cawley, Non-destructive testing - current capabilities and future directions, Proc. Inst. Mech. Eng. Pt. L-J. Mater.-Design Appl. 215 (2001) 213-223.

[6] L. Bai, A. Velichko, B.W. Drinkwater, Ultrasonic Characterization of Crack-Like Defects Using Scattering Matrix Similarity Metrics, Ieee Transactions on Ultrasonics Ferroelectrics and Frequency Control 62 (2015) 545-559.

[7] Y. Javadi, E. Mohseni, C.N. MacLeod, D. Lines, M. Vasilev, C. Mineo, E. Foster, S.G. Pierce, A. Gachagan, Continuous monitoring of an intentionally-manufactured crack using an automated welding and in-process inspection system, Materials \& Design 191 (2020) 108655.

[8] Y. Javadi, N.E. Sweeney, E. Mohseni, C.N. MacLeod, D. Lines, M. Vasilev, Z. Qiu, R.K.W. Vithanage, C. Mineo, T. Stratoudaki, S.G. Pierce, A. Gachagan, In-process calibration of a non-destructive testing system used for in-process inspection of multi-pass welding, Materials \& Design 195 (2020) 108981.

[9] R.A. Smith, Non-Destructive Testing (NDT) - Guidance Document: An Introduction to NDT Common Methods, BINDT, 2015.

[10] D.I. Lines, Y. Javadi, E. Mohseni, M. Vasilev, C.N. MacLeod, C. Mineo, R.W.

Vithanage, Z. Qiu, R. Zimermann, C. Loukas, E. Foster, S.G. Pierce, A. Gachagan, A flexible robotic cell for in-process inspection of multi-pass welds, Insight - Non-Destructive Testing and Condition Monitoring 62 (2020) 526-532.

[11] R. Holdstock, M. University of Wollongong. School of Mechanical, M. Engineering, Inducing Hydrogen Assisted Cold Cracking in High Strength Steel Weld Metal, University of Wollongong2009.

[12] Y. Javadi, M. Vasilev, C.N. MacLeod, S.G. Pierce, R. Su, C. Mineo, J. Dziewierz, A. Gachagan, Intentional weld defect process: From manufacturing by robotic welding machine to inspection using TFM phased array, AIP Conference Proceedings 2102 (2019) 040011. [13] P.J. Shull, Nondestructive evaluation: theory, techniques, and applications, CRC press2002.

[14] R. Pargeter, Evaluation of necessary delay before inspection for hydrogen cracks, Welding Journal 82 (2003) 321S-329S.

[15] D.G. AS, DNVGL-CG-0051: Non-destructive testing, Ultrasonic TestingNorway, 2015. 
[Type here]

[16] O. Barrera, D. Bombac, Y. Chen, T.D. Daff, E. Galindo-Nava, P. Gong, D. Haley, R. Horton, I. Katzarov, J.R. Kermode, C. Liverani, M. Stopher, F. Sweeney, Understanding and mitigating hydrogen embrittlement of steels: a review of experimental, modelling and design progress from atomistic to continuum, Journal of Materials Science 53 (2018) 6251-6290.

[17] Y. Javadi, Investigation of Clamping Effect on the Welding Residual Stress and Deformation of Monel Plates by Using the Ultrasonic Stress Measurement and Finite Element Method, Journal of Pressure Vessel Technology-Transactions of the Asme 137 (2015).

[18] P.J. Withers, M. Turski, L. Edwards, P.J. Bouchard, D.J. Buttle, Recent advances in residual stress measurement, International Journal of Pressure Vessels and Piping 85 (2008) 118-127.

[19] S. Bate, M. Smith, Determination of residual stresses in welded components by finite element analysis, Materials Science and Technology 32 (2016) 1505-1516.

[20] T. Boniszewski, Self-shielded arc welding, Woodhead Publishing Limited.1992.

[21] Y. Javadi, C.N. MacLeod, S.G. Pierce, A. Gachagan, D. Lines, C. Mineo, J. Ding, S.

Williams, M. Vasilev, E. Mohseni, R. Su, Ultrasonic phased array inspection of a Wire + Arc Additive Manufactured (WAAM) sample with intentionally embedded defects, Additive Manufacturing 29 (2019) 100806. 